\title{
Laser digital patterning of conductive electrodes using metal oxide nanomaterials
}

\author{
Vu Binh Nam ${ }^{1,2+}$, Trinh Thi Giang ${ }^{2 \dagger}$, Sangmo Koo ${ }^{3+}$, Junsuk Rho ${ }^{1,4^{*}}$ and Daeho Lee $2^{2^{*}}$ (I)
}

\begin{abstract}
As an alternative approach to the conventional deposition and photolithographic processes, the laser digital patterning (LDP) process, which is also known as the laser direct writing process, has attracted considerable attention because it is a non-photolithographic, non-vacuum, on-demand, and cost-effective electrode fabrication route that can be applied to various substrates, including heat-sensitive flexible substrates. The LDP process was initially developed using noble metal nanoparticles (NPs) such as Au and Ag because such materials are free from oxidation even in a nanosize configuration. Thus, the NPs must be fused together to form continuous conductive structures upon laser irradiation. However, common metals are easily oxidized th the nanoscale and exist in oxidized forms owing to the extremely large surface-to-volume ratio of NPs. Therefore, to fabricate conductive electrodes using common metal NPs via the LDP process, laser irradiation should be used to sinter the NPs and simultaneously induce additional photochemical reactions, such as reduction, and defect structure modification to increase the conductivity of the electrodes. This review summarizes recent studies on the LDP process in which metal oxide NPs, such as ITO, ZnO, $\mathrm{CuO}$, and $\mathrm{NiO}$, were exclusively utilized for fabricating conductive electrodes. The outlook of the LDP process for these materials is also discussed as a method that can be used together with or as a replacement for conventional ones to produce next-generation transparent conductors, sensors, and electronics.
\end{abstract}

Keywords: Laser, Digital patterning, ITO, $\mathrm{ZnO}, \mathrm{CuO}, \mathrm{NiO}$, Reductive sintering

\section{Introduction}

Lasers are widely used for various purposes, including presentation aids in daily life and industrial, medical, and scientific research and development because they are effective sources of heat [1-4] and illumination [59]. Lasers have the following unique characteristics that differentiate them from other heat and illumination systems. First, a laser can emit collimated light of a single wavelength owing to its spatial and temporal coherence. For this reason, a laser beam is focused and can be used

\footnotetext{
*Correspondence: jsrho@postech.ac.kr; dhl@gachon.ac.kr

tVu Binh Nam, Trinh Thi Giang and Sangmo Koo contributed equally to this work

${ }^{1}$ Department of Chemical Engineering, Pohang University of Science and Technology (POSTECH), Pohang 37673, South Korea

${ }^{2}$ Laser and Thermal Engineering Lab, Department of Mechanical Engineering, Gachon University, Seongnam 13120, South Korea

Full list of author information is available at the end of the article
}

as a localized heat or illumination source. Second, a laser with a specific wavelength can be applied for materials to selectively absorb or transmit the laser during laser processing because the absorption spectra of materials vary from one another. Moreover, the laser penetration depth can be controlled by employing lasers of different wavelengths [10]. Third, a laser is an extremely rapid heat source, and can increase the temperature much higher than conventional heating systems in a short time. Fourth, the output laser beam can be controlled using digitized parameters. In contrast to a typical heat source for which the temperature must pass continuously from a certain temperature to the final value, the laser can induce an immediate temperature change to the designated temperature through the setting of digital parameters. This characteristic allows the facile seamless integration of a laser with other fabrication tools. Fifth, the laser process can minimize the thermal damage to the 
substrates. Selecting a suitable laser wavelength prevents the laser from being absorbed directly into the substrate, whereas the laser-absorbing material can be heated to a very high peak temperature and cooled quickly. This makes the laser an effective tool for processing deposited materials on heat-sensitive substrates to fabricate flexible and stretchable devices [11-15]. Sixth, lasers can have various operating modes. A continuous-wave $(\mathrm{CW})$ laser emits light continuously, whereas a pulsed laser emits light for a certain duration at a specific repetition rate. Additionally, there are various pulse lasers, such as nanosecond, picosecond, and femtosecond lasers, that differ with regard to the pulse width of light, and lasers with the same pulse width can exhibit vastly different characteristics depending on the repetition rate. Lastly, the laser beam size and shape can be easily controlled by employing proper optical components. An extremely high power density can be achieved even with a low laser power because the laser power density is inversely proportional to the square of the beam diameter. On the other hand, nanomaterials exhibit unusual specific properties that differ significantly from those of bulk materials. One of the prominent phenomena occurring in nanoscale materials is melting-point depression. For example, while the melting temperature of bulk $\mathrm{Au}$ is $>1000{ }^{\circ} \mathrm{C}$, that of $<3-\mathrm{nm}$ Au NPs is as low as $150^{\circ} \mathrm{C}$ [11]. For the aforementioned reasons, the laser process of nanomaterials has been actively developed over the past two decades as a next-generation electrode fabrication method that does not require conventional photolithographic processes, vacuum equipment, or high-temperature processes $[3,4$, $12-16]$.

Laser digital patterning (LDP) is a photolithographyfree electrode fabrication and patterning method that exploits the foregoing unique characteristics of lasers and nanomaterials. The word "digital" here indicates that the laser is controlled by digitized parameters, and a digital image or computer-aided design (CAD) image is utilized for patterning instead of a physical patterning mask. This process is often called by different names, such as laser direct writing, laser direct patterning, and laser selective patterning, but the basic concepts and principles are similar. Although LDP covers, in a broad sense, all the fabrication methods of the laser-based additive and subtractive material patterning process regardless of the materials used, the meaning of LDP in this review is limited to an electrode patterning process using thin films coated with nanomaterials. The overall procedure of the LDP process is described in Sect. 2.1. It is noted that the detailed procedure of the LDP process can be partly different depending on the material used. In the early stages, the LDP process was developed using noble metal nanoparticles (NPs) such as Au and Ag [17-19] because such materials are free from oxidation even in a nanosize configuration. Thus, the NPs just need to be fused together to form continuous conductive structures via laser irradiation. However, owing to the high prices of the noble metals-which make the process noncompetitive as a low-cost, practical electronics fabrication methodthe need to use common metals for the LDP process is increasing. The most significant challenge in employing common metal NPs is that they are easily oxidized at the nanoscale and exist in oxidized forms owing to the large surface-to-volume ratio of NPs. Therefore, to fabricate conductive electrodes using common metal NPs via the LDP process, laser irradiation should sinter the NPs and simultaneously induce additional photochemical reactions, such as reduction, and defect structure modification to increase the conductivity of the electrodes. This review summarizes recent studies on the LDP process in which metal oxide NPs such as ITO, $\mathrm{ZnO}, \mathrm{CuO}$, and $\mathrm{NiO}$, were exclusively utilized for fabricating conductive electrodes. The outlook of the LDP process for these materials is also discussed in the context of next-generation transparent conductors, sensors, and electronics. It is worth to note that the word "sintering" refers to solidstate fusion, whereas the word "annealing," in a broader sense, covers melting phenomena. However, currently, the two words are used interchangeably, without a significant distinction of meaning. Therefore, in this review, these two words are quoted in the form used in the original references wherever possible.

\section{LDP process}

\subsection{Overall procedure of LDP process of metal oxide thin films}

Figure 1a shows the overall procedure of the LDP process for the thin film deposited using metal oxide NP ink. As mentioned previously, the detailed procedure of the LDP process depends on the material used, but this review focuses on the LDP process of thin films deposited using metal oxide NP ink. First, well-dispersed NP ink is prepared. "NP ink" refers to a solution where NPs are dispersed together in a solvent. Chemical additives, such as reducing agents and dispersants, are added and mixed if required. Then, the NP ink is deposited on substrates to form thin films via solution-processable methods such as spin coating, dip coating, doctor blading, and inkjet printing. In the selective laser irradiation step, the laser irradiates a specific portion of the thin film. Upon laser absorption, the temperature of the irradiated part increases rapidly, causing sintering of the NPs, along with a reduction reaction or defect structure modification. Finally, the washing process (if required), is applied. Because the laser-irradiated parts have enhanced adhesion to the substrate, only the laser-irradiated parts 


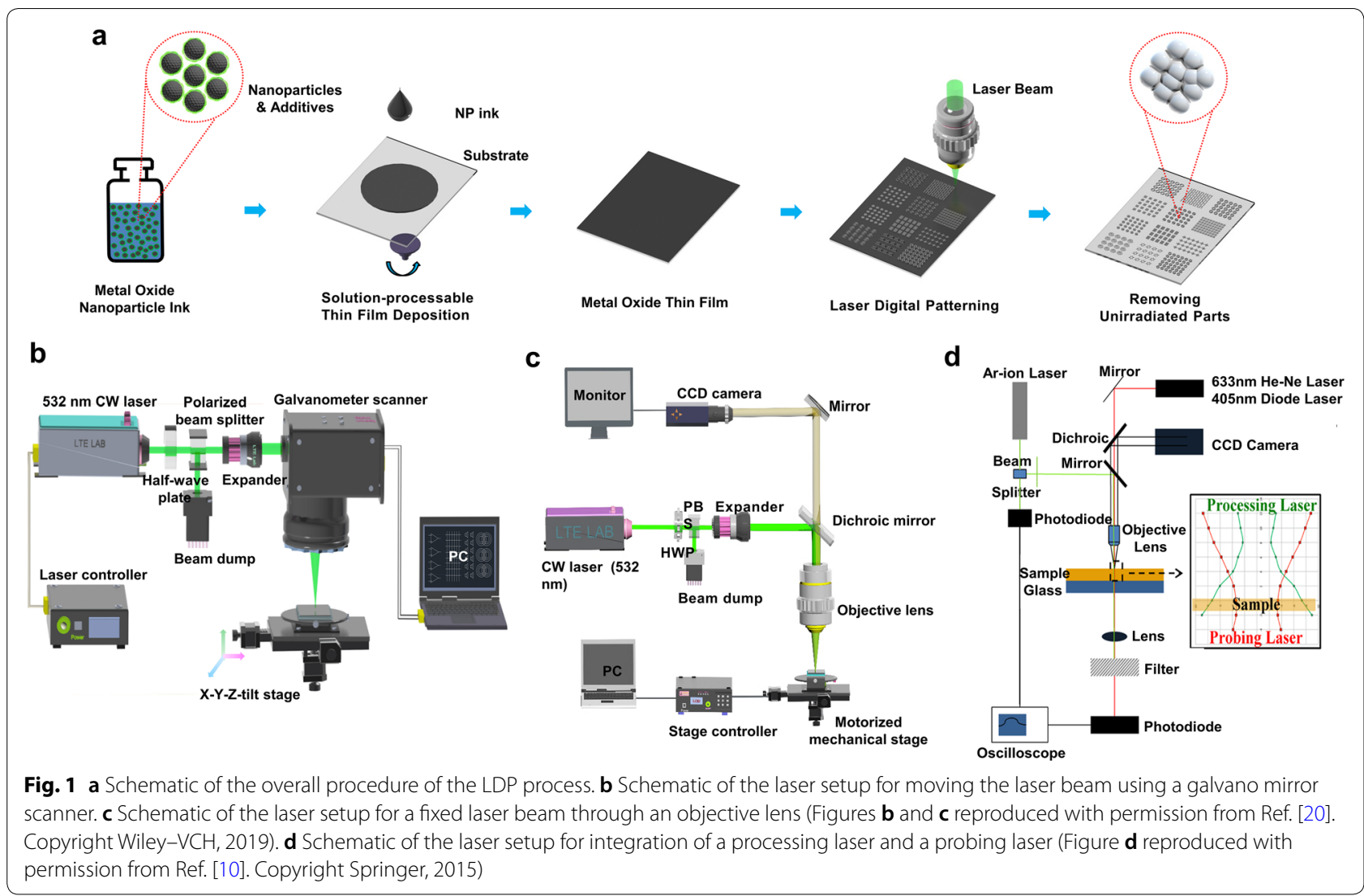

remain on the substrate after the washing process. A recent study [20] indicated that the strong adhesion between the electrodes and substrates of the laser-irradiated parts originates from that fact that substrate surfaces undergo partial melting and solidification during the LDP process; thus, the melted substrate instantly forms intimate contact with the sintered electrodes through the mechanical interlocking of the partially submerged electrode with the substrate. The solvent used in the washing process is generally the same solvent used for the NP ink or a solvent that is highly miscible with the ink solvent.

The LDP process has the following unique features compared with conventional electrode patterning processes. First, the process operation is simple, convenient, and time-saving, because no vacuum apparatus is generally required, even though an additional gas environment is required in special cases. It is also convenient to integrate the LDP process with other processes to compose an in-line continuous setup. Second, changing the pattern shape is extremely simple and cost-effective compared with the conventional photolithography process, because no physical mask is required. Third, as the washing process is simple, it is not necessary to use various etching solutions (which are usually not ecofriendly). Finally, chemical reactions or photochemical reactions that cannot be induced by the conventional heating system can occur during the laser process, because the laser allows rapid heating to a high peak temperature while minimizing the thermal impact on the substrate.

\subsection{Laser setup for LDP process}

In the selective laser irradiation step, the laser beam needs to move on the thin film. This can be achieved either via laser scanning using a galvano scanner (Fig. 1b) or by translating the thin film (Fig. 1c). In the former case, two galvanometer mirrors (one for each axis), control the position of the laser beam in the field of view. A telecentric lens allows the laser beam to be focused to different distances without changing the focus size. The scanning speed can reach several meters per second, and the scanning system can be easily integrated with a CAD program to generate arbitrary patterns. However, the minimum focused beam size is usually $>10 \mu \mathrm{m}$, even for short-wavelength laser beams. In the latter setup, the laser beam is focused through an infinity-corrected objective lens, while the thin film on a motorized mechanical stage moves under a fixed laser beam. The movement of the mechanical stage can be controlled by a CAD-integrated system. The laser beam diameter can be significantly smaller than that of the galvano 
mirror scanner if a large-numerical aperture objective lens is employed. Therefore, high-resolution patterning is achievable. Additionally, the latter setup is convenient for in situ monitoring of the laser processing area by a charge-coupled device camera. However, the scanning speed is limited by the performance of the mechanical stage and is significantly lower than the scanning speed of the former system. As an expanded setup, multiple lasers of different wavelengths (a processing laser and a probing laser) can be integrated together, as shown in Fig. 1d [10]. This setup allows in situ characterization of the thin film property changes during laser processing.

\section{LDP process of metal oxide NP thin films} 3.1 Indium-doped tin oxide (ITO)

ITO is the most widely used material for transparent conducting electrodes owing to its high conductivity and transparency $[21,22]$. Most of the thin films for television/computer screens and mobile device touch panels encountered in everyday life are made of ITO thin films deposited on rigid substrates via vacuum-based methods and patterned via photolithographic processes [23, 24]. The LDP process employing ITO NPs is a promising alternative to the conventional process, as it does not require vacuum equipment and allows the production of flexible ITO thin films. Although lasers have been used as post-processing tools for vacuum-deposited ITO thin films [25-27], studies on the LDP process of ITO films prepared using NP ink have not been actively performed. Most of the studies introduced in this section focused on improving the conductivity while maintaining the transparency of ITO NP films via laser irradiation, rather than focusing on selective patterning. However, research on fabricating transparent electrodes by applying laser processes to thin films produced using ITO NP ink is considered to be worthwhile, because it is clearly differentiated from conventional processes and provides fundamental insights regarding the patterning of the material.

The carrier density of ITO is determined by active $\mathrm{Sn}$ dopants and $\mathrm{O}$ vacancies, whose generation reaction depends on the temperature [28, 29]. Therefore, the temperature increase in ITO NPs induced by the laser not only sinters the NPs, fusing them together, but also induces carrier density changes. UV lasers are effective for ITO processing because their photon energy is larger than the bandgap of ITO (3.5-4.3 eV); thus, interband absorption occurs. Park et al. used nanosecond $\mathrm{KrF}$ excimer laser irradiation $(\lambda=248 \mathrm{~nm}$, pulse width $=25 \mathrm{~ns})$ to enhance the electrical conductivity of an ITO NP thin film on a heatsensitive polyethylene terephthalate (PET) substrate [30]. A 200-nm-thick ITO thin film with a high sheet resistance $\left(\sim 900 \mathrm{k} \Omega ~ s q^{-1}\right)$ was fabricated on PET by spin-coating an ethanol-based ITO NP ink. Subsequent single-pulse laser irradiation of fluence in the range of $80-160 \mathrm{~mJ} \mathrm{~cm}{ }^{-2}$ fused ITO NPs to form crystallized grains. Consequently, the sheet resistance was reduced to approximately $500 \Omega \mathrm{sq}^{-1}$ (Fig. 2a). Even though the transmittance of the ITO film decreased by up to $24 \%$ from the maximum value, the optical transparency level of the film was still comparable to that of the sputtered film (Fig. 2b). Additionally, infrared (IR) lasers can be used for the laser processing of ITO thin films, because free carriers that exist in the film allow the intraband absorption of the IR laser in ITO [31]. KÖniger et al. reported that $\mathrm{CO}_{2}$ laser irradiation $(\lambda=10.6 \mu \mathrm{m})$ improved the electrical conductivity of ITO NP thin films coated on a PET substrate [32]. The sheet resistance of the laser processed ITO thin film was reduced by a factor of 30 compared with that of an as-prepared one, while its transparency exhibited only a slight decrease of approximately $5 \%$ and remained above $75 \%$ at the laser fluence of $40 \mathrm{~kJ} \mathrm{~m}^{-2}$. Furthermore, the electrical conductivity exhibited high stability under bending deformation owing to its porous structures [32]. Serkov et al. used a combination of gravure printing of ITO NP ink and a laser sintering process to generate highly conductive films without affecting the PET substrate [33]. A laser $(\lambda=1750 \mathrm{~nm}$, pulse width $=6 \mathrm{ps}$, pulse repetition rate $=40 \mathrm{MHz}$ ) was applied to the ITO film with fluence variations $\left(0.35-0.8 \mathrm{~J} \mathrm{~m}^{-2}\right)$. The sheet resistance decreased significantly from $6 \mathrm{k} \Omega \mathrm{sq}^{-1}$ at a fluence of $0.35 \mathrm{~J} \mathrm{~m}^{-2}$ to $0.1 \mathrm{k} \Omega \mathrm{sq}^{-1}$ at a fluence of $0.7 \mathrm{~J} \mathrm{~m}^{-2}$, which was attributed to the laser-induced removal of the dielectric 3-methacryloxypropyltrimethoxysilane (MPTS) binder in the ink film and the sintering of the NPs. However, the transparency of the irradiated film became more opaque with an increase in the laser fluence owing to the increased amount of metallic phases after the laser process, as shown in Fig. 2c, d [33]. By optimizing the laser parameters, a low sheet resistance of $0.5 \mathrm{k} \Omega \mathrm{sq}^{-1}$ was achieved, while the transmittance exhibited a slight variation, at a laser fluence of $0.49 \mathrm{~J} \mathrm{~m}^{-2}$.

Pan et al. used a near-IR CW fiber laser $(\lambda=1.5 \mu \mathrm{m})$ to sinter ITO NPs and achieved a resistivity of $1.3 \times 10^{-3} \Omega \mathrm{cm}$, which is $4-5$ times higher than that of commercially available sputtered ITO films [29]. They employed a cylindrical lens to form an elliptical beam to increase the processing area. By introducing Ar and air mixtures as background gases, the dependencies of the ITO sheet resistance and transmittance on the gas composition (Fig. 2e, f), as well as the mechanism for controlling the carrier density associated with defect kinetics in the ITO thin film, were investigated. 
a

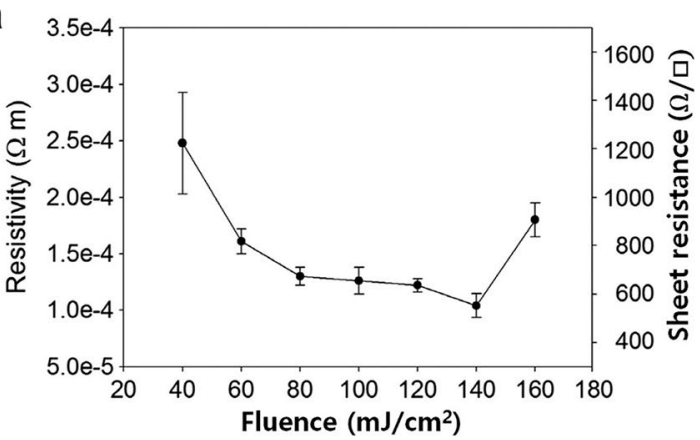

C

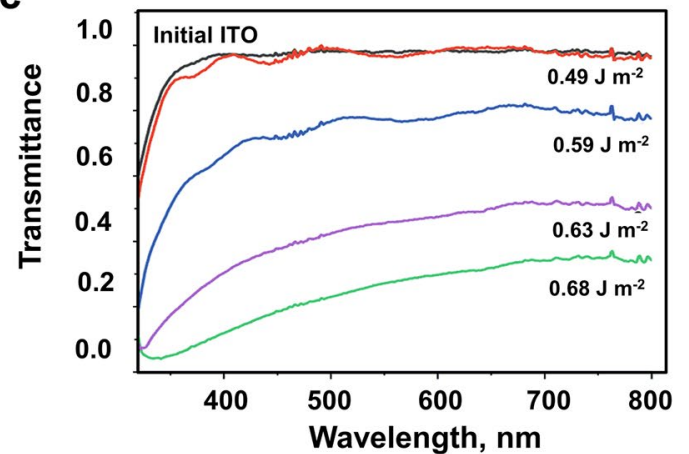

e

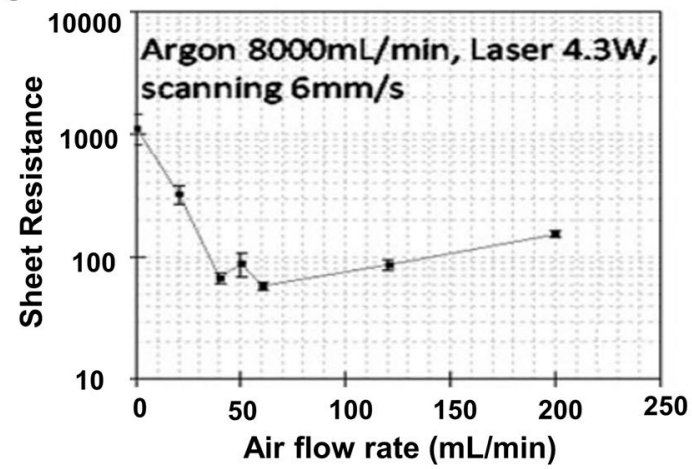

b

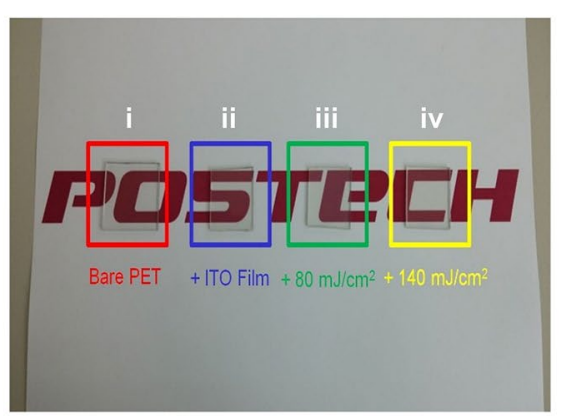

d

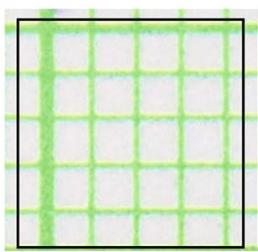

(i)

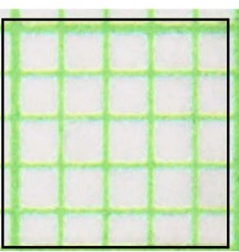

(ii)

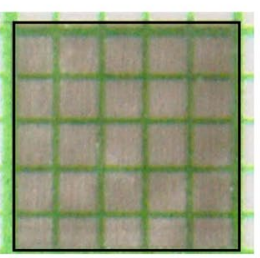

(iii) f

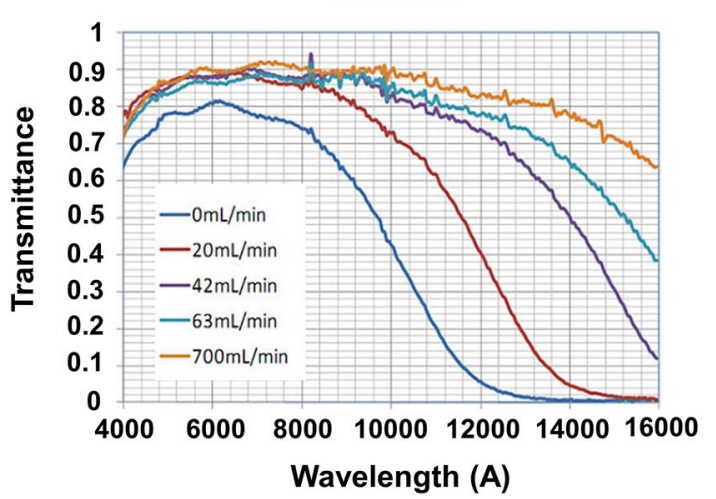

Fig. 2 a Variation of the electrical resistivity (sheet resistance) of the laser-irradiated ITO film depending on the laser fluence of a single pulse. $\mathbf{b}$ Optical image to compare the transparency of thin films after the laser process (i: bare PET; ii: ITO film only; iii: ITO film after a single laser pulse at $80 \mathrm{~mJ} \mathrm{~cm}^{-2}$; iv: ITO film after a single laser pulse at $140 \mathrm{~mJ} \mathrm{~cm}^{-2}$ ) (a and $\mathbf{b}$ reproduced with the permission from Ref. [30]. Copyright Elsevier, 2015). c Optical transmission spectra of ITO thin films with different incident laser fluences. $\mathbf{d}$ Photographic image of a gravure-printed ITO film irradiated within the areas indicated by the black lines at different laser fluences (i: $0.49 \mathrm{~J} \mathrm{~m}^{-2}$; ii: $0.56 \mathrm{~J} \mathrm{~m}^{-2}$; iii: $0.65 \mathrm{Jm}^{-2}$ ). Paper with millimeter squares was used as a background (Figures $\mathbf{c}$ and $\mathbf{d}$ reproduced with permission from Ref. [33], Copyright Nature Publishing Group, 2019). e Dependence of the sheet resistance of the laser-annealed ITO NP thin film on air-Ar mixed background gas in a quartz enclosure. f Transmittance data for a laser-annealed ITO NP thin film measured under different air flows with a fixed Ar flow at $8000 \mathrm{~mL} / \mathrm{min}$ (e and $\mathbf{f}$ reproduced with permission from Ref. [29]. Copyright Springer, 2011)

\section{$3.2 \mathrm{ZnO}$}

$\mathrm{ZnO}$ is one of the major semiconductors in the field of nanoscience and nanoengineering and is used for various electronics, photonics, optics, and sensors for the following reasons: (1) $\mathrm{ZnO}$ is an abundant, nontoxic, and lowcost material; (2) $\mathrm{ZnO}$ nanostructures can be synthesized via a simple method at a low temperature; and (3) the optoelectronic properties of $\mathrm{ZnO}$ NP films can be easily tuned through doping with various dopants. In particular, doped $\mathrm{ZnO}$ and undoped $\mathrm{ZnO}$ have long been studied as substitutes for ITO, and related research is still underway. However, few studies have been performed on the laser processing of solution-processed NP-based $\mathrm{ZnO}$ thin films, whereas studies on the laser annealing of $\mathrm{ZnO}$ thin 
films deposited through sputtering, evaporation, sol-gel processes, and pulsed laser deposition [34-41] have been actively reported. The researches presented below deal with $\mathrm{ZnO}$ thin films deposited using $\mathrm{ZnO}$ NPs but the final washing process illustrated in Fig. 1 was not applied. However, it is worth introducing the researches in this chapter, because the fundamental concept and purpose of the laser process match the scope of this review in that laser irradiation is applied to the NPs and induces additional photochemical reactions simultaneously to control the conductivity of the electrodes.

For the material to absorb the laser via interband absorption, lasers with photon energies equal to or higher than the bandgap of the material are required. Because the bandgap of $\mathrm{ZnO}$ is $\sim 3.3 \mathrm{eV}$, ultraviolet (UV) lasers with wavelengths shorter than $375 \mathrm{~nm}$ $\left(\frac{1240 \mathrm{eV} \mathrm{nm}}{3.3 \mathrm{eV}} \approx 375 \mathrm{~nm}\right)$ can be utilized to process $\mathrm{ZnO}$ thin films. Pan et al. reported the laser sintering of solution-deposited $\mathrm{ZnO}$ NPs to produce an active layer of a high-performance n-type field-effect transistor (FET) [42]. The ZnO NP ink was prepared by dispersing commercial NPs $(<100 \mathrm{~nm})$ in ethanol and deposited via spin coating on the pre-patterned metal contacts, which were defined on an $\mathrm{SiO}_{2}$ gate dielectric formed on a highly doped n-type $\mathrm{Si}$ wafer. The $\mathrm{ZnO}$ layer was then irradiated by a single pulse of a flat-top excimer laser beam $(\lambda=248 \mathrm{~nm}$, pulse width $=20 \mathrm{~ns})$ at a fluence of $160 \mathrm{~mJ} \mathrm{~cm}^{-2}$ (Fig. 3a). Upon laser irradiation under ambient conditions, the NPs melted to form polycrystalline, rounded, and smooth agglomerations (Fig. 3b). Photoluminescence measurements (Fig. 3c) confirmed that the high photon energy of the laser broke chemical bonds, created $\mathrm{O}$ vacancies, and removed excess $\mathrm{O}$, reducing the electrical resistance of the $\mathrm{ZnO}$ layer by three orders of magnitude and increasing the mobility and on/off ratio of the ZnO FET by three to four orders of magnitude. It is noted that only single-pulse laser irradiation resulted in a similar effect to $\sim 700{ }^{\circ} \mathrm{C}$ furnace annealing [43] on the mobility of the $\mathrm{ZnO}$ FET. In another study, Lee et al. used a high-repetition UV picosecond laser $(\lambda=355 \mathrm{~nm}$, pulse width $=12 \mathrm{ps}$, pulse repetition rate $=80 \mathrm{MHz}$ ) to increase the electrical conductivity of a transparent $\mathrm{ZnO}$ thin film that was deposited with well-dispersed, high-concentration $\mathrm{ZnO} N \mathrm{NP}$ ink containing very small $(\sim 6 \mathrm{~nm}) \mathrm{NPs}$ [44]. The ZnO NPs synthesized in the methanol-based solution were re-dispersed in a longer-chain alcohol (1-pentanol) to prevent agglomeration of the NPs. Upon laser irradiation under ambient conditions, the temperature of the $\mathrm{ZnO} \mathrm{NP}$ thin film increased sufficiently to break the $\mathrm{Zn}-\mathrm{O}$ bonds and form additional $O$ vacancies. Simultaneously, the NPs were fused to each other, creating continuous current paths, which increased the conductivity. Laser sintering with an Ar flow further enhanced the conductivity of the $\mathrm{ZnO}$ thin film (although the transmittance of the resulting thin film was reduced), as it promoted a net increase in $\mathrm{O}$ vacancies by preventing the oxidation of $\mathrm{ZnO}$ by ambient air (Fig. 3d, e). Adjusting the ratio of air to Ar as background gases can produce a highly conductive $\mathrm{ZnO}$ thin film while maintaining high transparency. The lowest resistivity achieved with the undoped $\mathrm{ZnO}$ thin film in this study was $4.75 \times 10^{-2} \Omega \mathrm{cm}$, which was five orders of magnitude lower than that of a furnace-annealed $\mathrm{ZnO}$ film [45]. Because the unirradiated parts of the $\mathrm{ZnO}$ thin film were almost insulators, arbitrary conductive $\mathrm{ZnO}$ patterns could be generated directly on the substrate via laser processing (Fig. 3f).

As mentioned previously, the optoelectronic properties of $\mathrm{ZnO}$ films can be easily tuned via doping with various dopants, such as $\mathrm{Al}$ [46], Ga [47, 48], and Li [49]. Among the dopants, laser annealing of Al-doped $\mathrm{ZnO}$ (AZO) thin films prepared via vacuum-based deposition or sol-gel processes have been extensively investigated, and the optoelectronic properties of the resulting films are comparable to those of ITO films. For instance, Hamali et al. used excimer laser irradiation $(\lambda=248 \mathrm{~nm}$, pulse width $=25 \mathrm{~ns}$ ) to enhance the conductivity of a sputtered AZO film [50]. After laser processing at a fluence of $125 \mathrm{~mJ} \mathrm{~cm}^{-2}$, the resistivity of the thin film was reduced from $1 \times 10^{-3}$ to $5 \times 10^{-4} \Omega \mathrm{cm}$, while the average visible transmission was increased from 85 to $90 \%$. In contrast to the case of undoped $\mathrm{ZnO}$ thin films, lasers with a wide wavelength range (from UV to IR) can be used for the processing of doped $\mathrm{ZnO}$ films, owing to the absorption of free carriers of the dopants and the modification of the band structure due to doping. For example, Hsiao et al. used an 808-nm CW laser [51], Xu et al. used a 1064-nm $\mathrm{CW}$ laser [52], and Huang et al. used a 532-nm nanosecond laser [53] for AZO annealing. However, thus far, no LDP process for a doped $\mathrm{ZnO}$ thin film prepared using NP ink has been reported, to the best of our knowledge.

More recently, several studies indicated that the LDP of $\mathrm{ZnO}$ thin films allows the fabrication of transient electronic devices that can disappear completely or partly upon exposure to water at prescribed rates or within a prescribed time period [54-56]. Shou et al. reported a low-cost laser process for $\mathrm{ZnO} \mathrm{NP}$ films to fabricate $\mathrm{Zn}$ conductors on a bioresorbable sodium carboxymethyl cellulose (Na-CMC) substrate [55]. Although Zn NPs were used as starting materials for the laser process in this study, oxide-shell layers were formed naturally on the $\mathrm{Zn} \mathrm{NPs,} \mathrm{yielding} \mathrm{ZnO}$, which made the sintering process difficult. The authors prepared a Zn NP-coated glass slide, which was gently placed on a Na-CMC substrate, and applied a $1065-\mathrm{nm} \mathrm{CW}$ laser beam driven by a galvano scanner through the top glass slide. The laser 
a

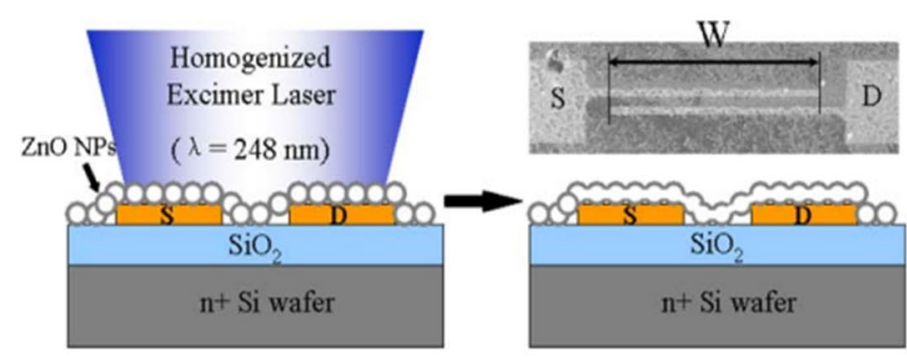

C

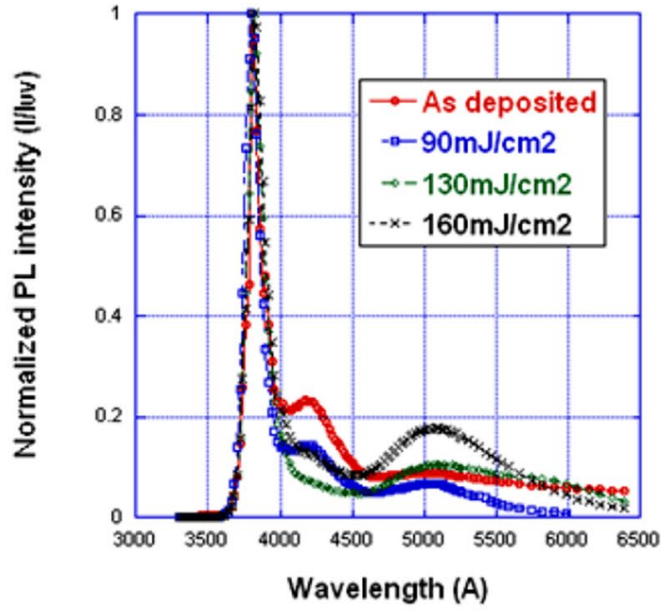

e

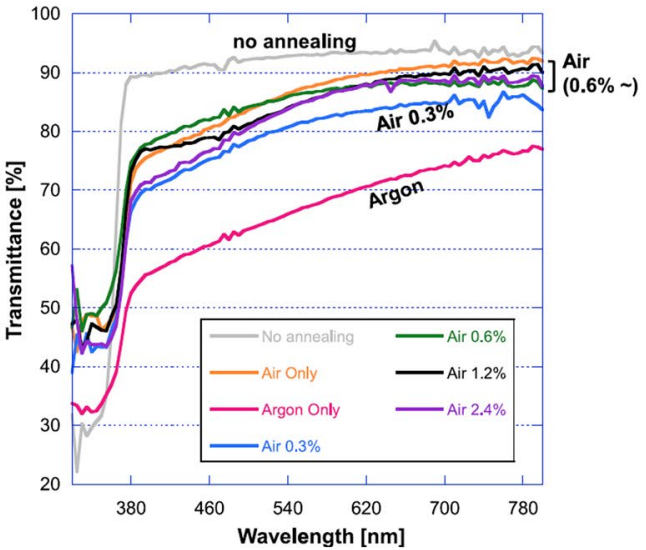

b

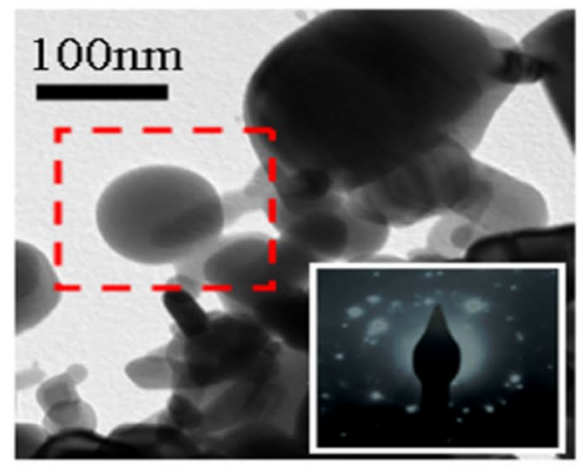

d

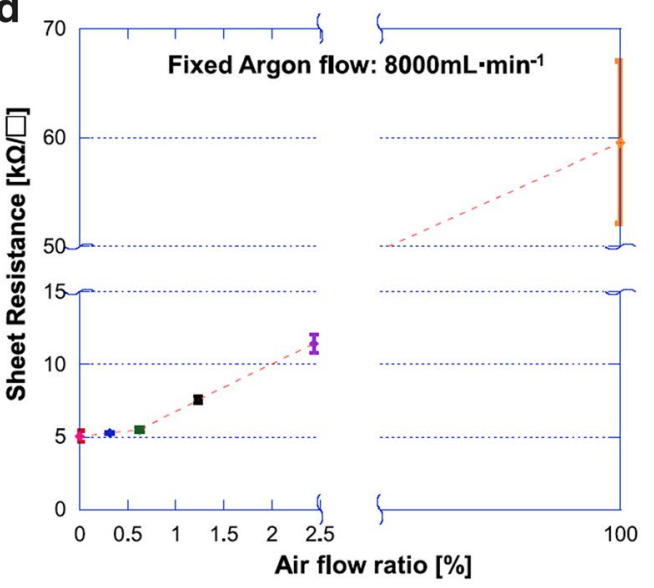

f

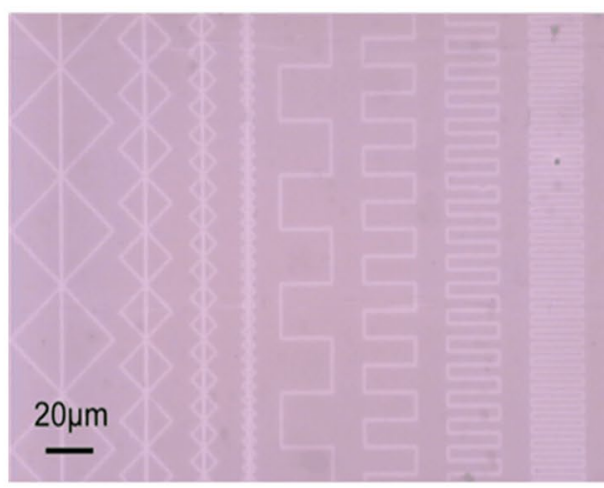

Fig. 3 a Schematic side view of the excimer laser annealing process and the ZnO NP field-effect transistor structure. S and D indicate the source and drain electrodes, respectively. The top right inset presents a top-view SEM image of transistor electrodes with a layer of deposited ZnO NPs. b Transmission electron microscopy (TEM) image of the ZnO NP film after excimer laser irradiation. The inset shows the diffraction pattern for the marked region. $\mathbf{c}$ Room-temperature photoluminescence spectra of the $\mathrm{ZnO}$ thin film with and without laser annealing (a-c reproduced with permission from Ref. [42]. Copyright Springer, 2009). d Sheet resistance of the ZnO thin film depending on the background gas during laser annealing. e Transmittance of $\mathrm{ZnO}$ thin films annealed in background gases with different compositions. $\mathbf{f}$ Optical microscope image of 1.5- $\mu \mathrm{m}$-line width patterns generated on the ZnO thin film (d-f reproduced with permission from Ref. [44]. Copyright Springer, 2012) 


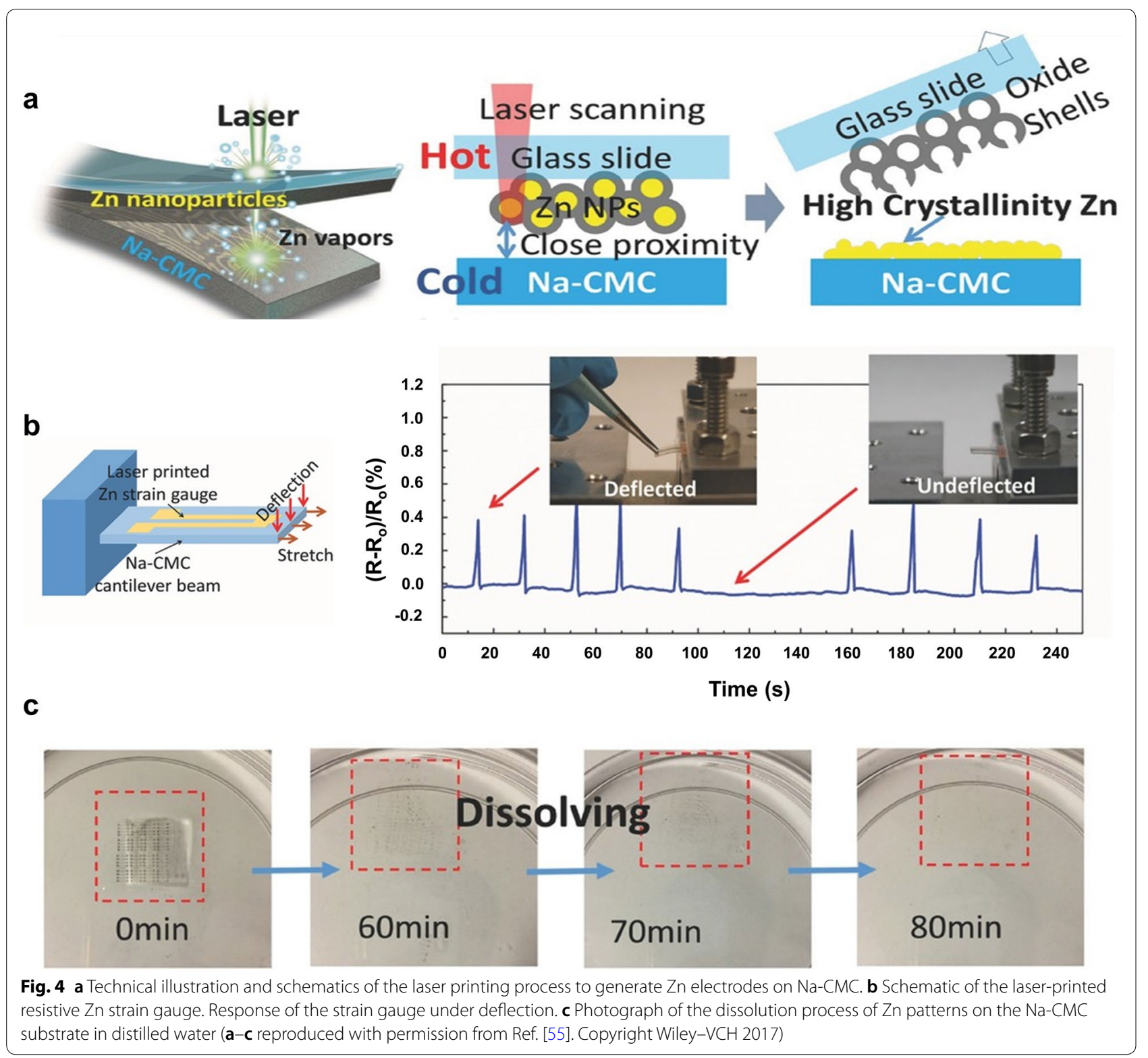

irradiation removed the oxide shell layers of the Zn NPs and then transferred arbitrary electrode features onto the receiving $\mathrm{Na}-\mathrm{CMC}$ substrate (Fig. 4a). The resulting resistivity of the laser-irradiated $\mathrm{ZnO}$ electrode was approximately $0.9 \times 10^{-4} \Omega \mathrm{cm}$, which is 15 times higher than that of bulk $\mathrm{Zn}\left(6 \times 10^{-6} \Omega \mathrm{cm}\right)$. The usefulness of the $\mathrm{Zn}$ electrodes was demonstrated by fabricating a strain gauge that could detect both stretching and deflection (Fig. 4b). The $\mathrm{Zn}$ electrodes on the substrate dissolved completely in water within $100 \mathrm{~min}$ (Fig. 4c).

\section{$3.3 \mathrm{CuO}$}

$\mathrm{Cu}$ has received considerable attention as an alternative to ITO and noble metals $(\mathrm{Au}, \mathrm{Ag})$ owing to its remarkably low cost and superior electrical conductivity [57-62]. $\mathrm{Cu}$ has a low electrical resistivity $(1.68 \mu \Omega \mathrm{cm})$, which is similar to that of $\mathrm{Ag}(1.58 \mu \Omega \mathrm{cm})$ and lower than that of $\mathrm{Au}(2.21 \mu \Omega \mathrm{cm})$, but is 100 times less expensive because it is 1000 times more abundant [63]. Moreover, $\mathrm{CuO}$ nanostructures with various morphologies and dimensions can be easily synthesized using numerous techniques, such as chemical solutions [64-66], the hydrothermal method [67-69], and the sol-gel method [70-72]. However, nanoscale $\mathrm{Cu}$ materials are easily 
oxidized, becoming nonstoichiometric $\mathrm{CuO}_{\mathrm{x}}$ (e.g., $\mathrm{Cu}_{2} \mathrm{O}$, $\mathrm{CuO}$ ), under ambient conditions because of their low oxidation potential energy. Therefore, many studies have been conducted to enable the use of $\mathrm{Cu}$ nanomaterials by reducing the synthesized $\mathrm{CuO}$ using microwaves [73], atmospheric-pressure glow (APG) discharge [74], and intense pulsed light (IPL) [75, 76]. However, there are limitations; e.g., microwave processing requires a high temperature and a large amount of electricity; vacuum conditions and a high-temperature environment are required for APG discharge-based processing; the
IPL method requires an additional photomask to create a fixed electrode pattern. LDP process-induced reductive sintering (LRS) of the $\mathrm{CuO} \mathrm{NP}$ film with the aid of reducing agents was proposed as a new alternative for fabricating $\mathrm{Cu}$ patterns without high-temperature, high-vacuum environments or photolithographic processes.

Kang et al. reported a simple and low-cost fabrication route to generate $\mathrm{Cu}$ electrode patterns using the LRS process [77]. $\mathrm{CuO}$ ink was prepared by dispersing $\mathrm{CuO}$ NPs into a polyvinylpyrrolidone (PVP) and ethylene glycol (EG) mixture and spin-coated onto a
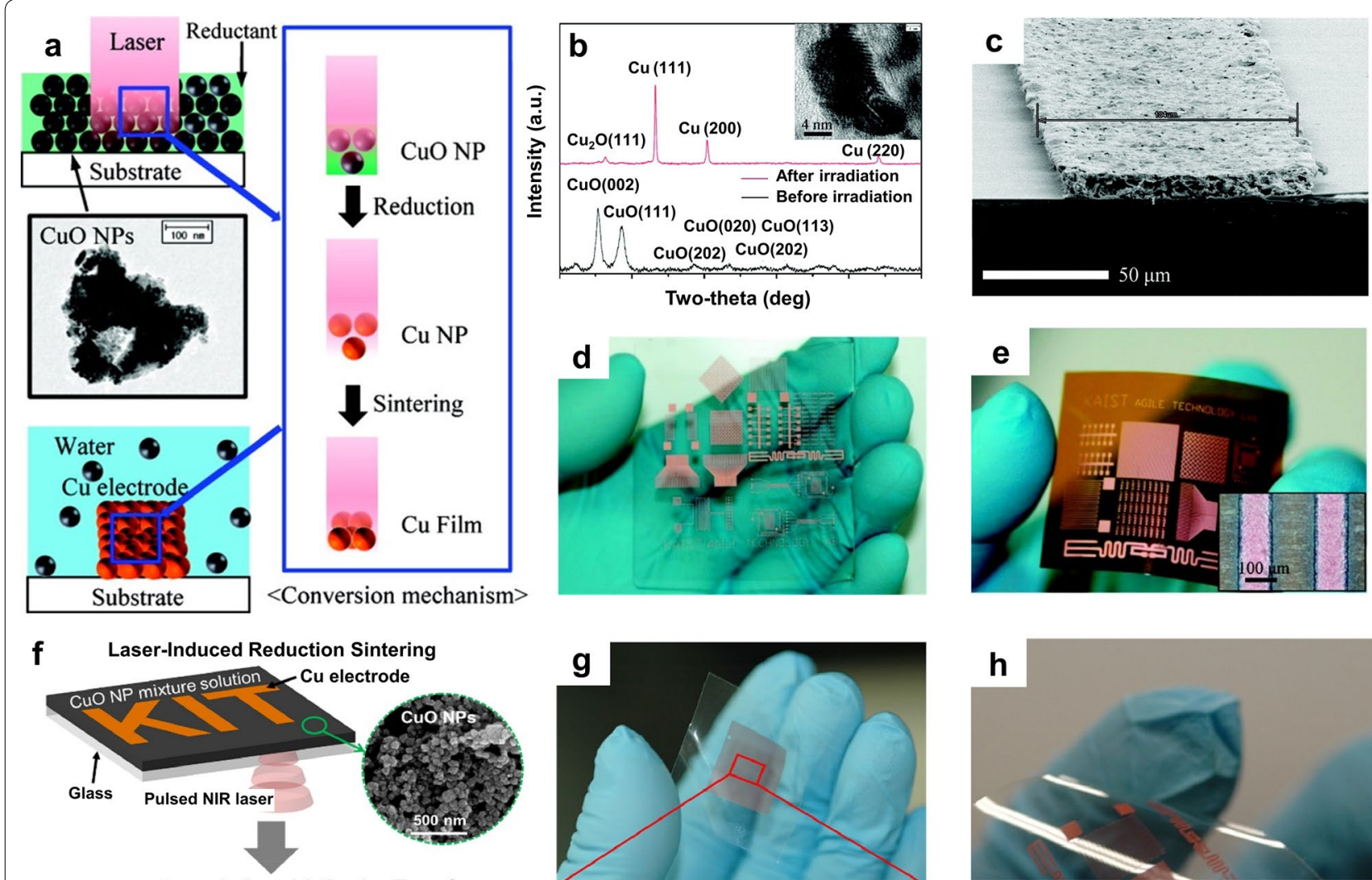

Laser-Induced Adhesive Transfer
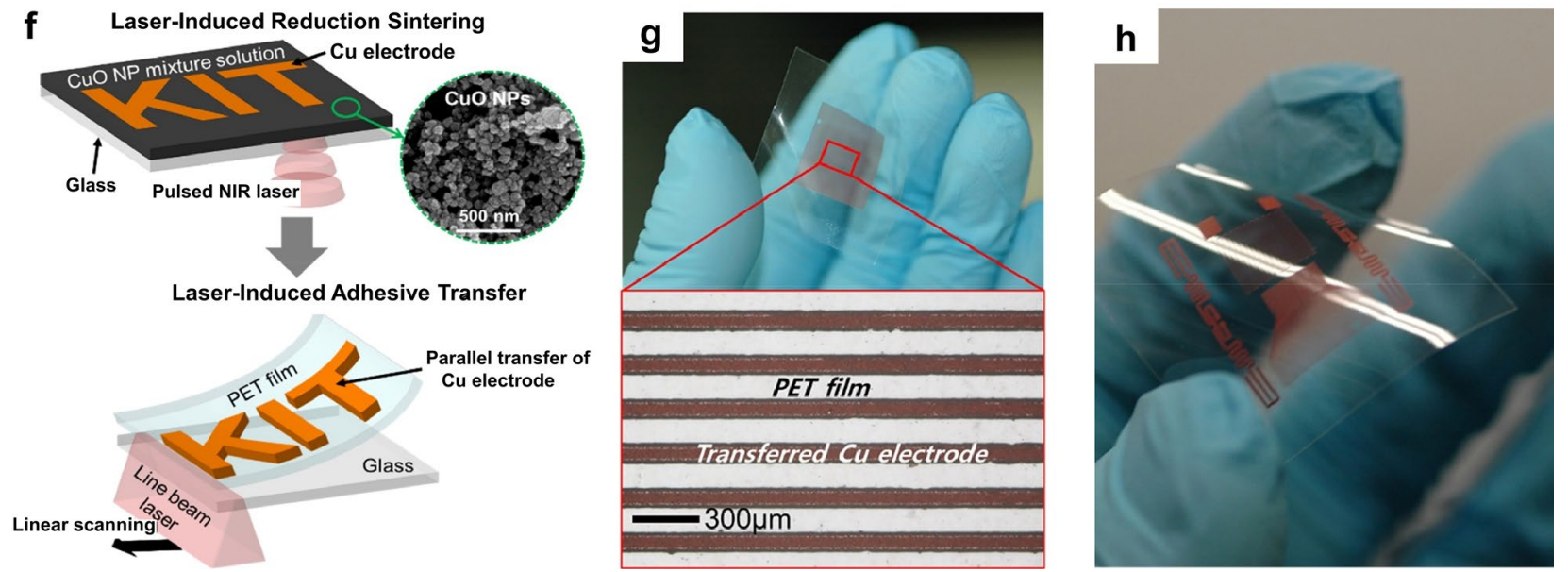

Fig. 5 a Schematic of the proposed process for the conversion of CuO NPs into a Cu film via photochemical reduction and photothermal agglomeration. b XRD analysis results obtained before and after laser irradiation; (inset) TEM image of a Cu film processed using a pulsed laser. $\mathbf{c}$ Cross-sectional SEM image of the Cu electrode. $\mathbf{d}$, e Photograph of Cu electrode patterns on a glass substrate and a PI substrate, respectively (a-e reproduced with permission from Ref. [77]. Copyright American Chemical Society 2011). f Schematic of the fabrication procedures for laser-induced reductive sintering and laser-induced adhesive transfer. $\mathbf{g}$ Photograph and microscope image of Cu NP electrodes transferred to a PET receiver film at a laser power of $2 \mathrm{~W}$ and a laser scanning speed of $2000 \mathrm{~mm} \mathrm{~min}^{-1}$. $\mathbf{h}$ Photograph of arbitrary Cu electrode patterns transferred to the PET film (f-h reproduced with permission from Ref. [81]. Copyright Elsevier, 2018) 
UV-ozone-treated glass or flexible polyimide (PI) substrate. Because of the narrow bandgap of $\mathrm{CuO}(1.1-$ $1.2 \mathrm{eV}$ ), 1070-nm laser irradiation (either CW or pulsed mode) was absorbed well by the thin $\mathrm{CuO}$ film through interband absorption. During the laser process, EG generated acetaldehyde via dehydration, and $\mathrm{CuO}$ NPs were converted into $\mathrm{Cu}$ NPs (Fig. 5a). Reduction from $\mathrm{CuO}$ to $\mathrm{Cu}$ was confirmed by a color change (from dark to reddish) and by X-ray diffraction (XRD) measurements (Fig. 5b) and indicated the low resistivity of the $\mathrm{Cu}$ electrode pattern $(31 \mu \Omega \mathrm{cm}$ ) (Fig. $5 \mathrm{c}-\mathrm{e})$. Lee et al. examined the reduction tendency of $\mathrm{CuO}$ under pulsed laser irradiation $(\lambda=1070 \mathrm{~nm}$, pulse repetition rate $=1 \mathrm{MHz})$ after dissolving PVP as a reducing agent in different solvents, such as isopropyl alcohol, ethanol, and 1-butanol [78]. Upon laser irradiation, the PVP was decomposed into amorphous $\mathrm{C}$ and other materials by thermal energy in a hydrate solvent. Among the other generated materials, carboxylic acid reduced $\mathrm{CuO}$ to $\mathrm{Cu}$, and residues such as amorphous $\mathrm{C}$, hydrogen oxide, and carbon dioxide were removed by the washing process or evaporated during the laser processing. The as-prepared thin film composed of exothermic solvents after the LRS process exhibited a better morphology and higher conductivity than other films composed of endothermic solvents. Additionally, a larger amount of conductive electrodes could be realized with higher molar ratios and larger amounts of PVP in the $\mathrm{CuO}$ ink. By optimizing the PVP concentrations and solvents, a $\mathrm{Cu}$ electrode with a low specific resistance of $13 \mu \Omega \mathrm{cm}$ was achieved. Mizoshiri et al. fabricated $\mathrm{Cu}$ and $\mathrm{Cu} / \mathrm{Cu}_{2} \mathrm{O}$ electrodes by controlling the scanning speed (500-1000 $\mu \mathrm{m} \mathrm{s}^{-1}$ ) and pulse energy (0.36-1.2 $\mathrm{nJ})$ during the LRS process using a femtosecond laser $(\lambda=780 \mathrm{~nm}$, pulse width $=120 \mathrm{fs}$, pulse repetition rate $=80 \mathrm{MHz})[79,80]$. The electrical resistance of the $\mathrm{Cu}$ electrodes exhibited metal-like electrical conductivity behavior with a positive temperature coefficient of resistance, whereas that of the $\mathrm{Cu}_{2} \mathrm{O}$ electrodes exhibited semiconductor-like behavior with a negative temperature coefficient of resistance. These properties can be used to fabricate temperature-sensing materials.

Processing on a material substrate having a low glass transition temperature $\left(\mathrm{T}_{\mathrm{g}} \approx 80{ }^{\circ} \mathrm{C}\right)$, such as PET, is another challenge. Back et al. developed a new approach for $\mathrm{Cu}$ electrode patterning on PET substrates that combined a laser-induced adhesive transfer process with the LRS technique (Fig. 5f) [81]. First, a Cu electrode was fabricated on a glass donor by inducing reduction and agglomeration of the $\mathrm{CuO}$ NP film via irradiation with a focused beam of a pulsed fiber laser $(\lambda=1070 \mathrm{~nm}$, pulse repetition rate $=300 \mathrm{kHz}$ ). Subsequently, the $\mathrm{Cu}$ electrode formed in the previous step was transferred to the PET substrate via 808-nm CW laser-induced adhesive transfer between the PET film and the donor surface (Fig. 5g, h) [81]. The resulting $\mathrm{Cu}$ electrodes exhibited a low resistivity of $30 \mu \Omega \mathrm{cm}$, with strong adhesion to the PET substrate.

More recent studies indicated that the implementation of the LRS process for a $\mathrm{CuO}$-based mixture containing $\mathrm{NiO}[82,83]$ and graphene oxide (GO) [84] allows the fabrication of multi-element composites with various functional properties. Mizoshiri et al. fabricated p- and n-type thermoelectric micropatterns using the LRS process of $\mathrm{CuO} / \mathrm{NiO}$ NP films (Fig. 6a) [83]. The $\mathrm{CuO} / \mathrm{NiO}$ $\mathrm{NP}$ ink was prepared by mixing PVP, CuO NPs, $\mathrm{NiO}$ NPs, and EG and was spin-coated onto the glass substrate. By controlling the scanning speed of the focused femtosecond laser $(\lambda=780 \mathrm{~nm}$, pulse repetition rate $=80 \mathrm{MHz})$ on the $\mathrm{CuO} / \mathrm{NiO} \mathrm{NP}$ film, $\mathrm{Cu}_{2} \mathrm{O} / \mathrm{NiO}$ or $\mathrm{Cu} / \mathrm{Ni}$ electrodes could be fabricated. $\mathrm{Cu}_{2} \mathrm{O} / \mathrm{NiO}$ electrodes fabricated with scanning speeds of 1 and $20 \mathrm{~mm} \mathrm{~s}^{-1}$ exhibited $\mathrm{p}$ - and n-type thermoelectric properties, respectively. The selective direct writing process for $\mathrm{p}$-/ $\mathrm{n}$-type thermoelectric materials indicated the potential for application to various thermoelectric-type sensors. Watanabe et al. synthesized a reduced $\mathrm{GO}(\mathrm{rGO}) / \mathrm{Cu}$ hybrid structure by applying the LRS method to a water-dispersion mixture of $\mathrm{GO}$ and $\mathrm{CuO}$ nanorods (NR) [84]. GO was used as a reducing agent and as a gel-like binder to form a coating film. In this study, the well-known reaction involving the reduction of $\mathrm{CuO}$ with $\mathrm{C}$ via heat treatment was exploited. During the laser irradiation, the oxidized structure of GO was easily changed into rGO, while the $\mathrm{CuO} N R s$ were reduced to $\mathrm{Cu}$. The hybrid $\mathrm{rGO} / \mathrm{Cu}$ and $\mathrm{GO} / \mathrm{CuO}$ structures were used for an IR photosensor. The concept of converting $\mathrm{CuO}_{\mathrm{x}}$ nanostructures into $\mathrm{Cu}$ through the LRS process has been extended to the repetitive reuse of nanomaterials (i.e., nano-recycling) via the photothermochemical reduction process [85]. Applying 532-nm CW laser irradiation to the oxidized $\mathrm{Cu}$ nanowire (NW) electrode layer with additional EG on the layer induced dehydration of EG, generating acetaldehyde, which reduced $\mathrm{CuO}$ to $\mathrm{Cu}$, with diacetyl and water as byproducts (Fig. $6 \mathrm{~b}$ ). The recycled $\mathrm{Cu}$ electrodes exhibited excellent conductivity, with increased resistance to the external environment owing to the enhanced NW junctions. The authors confirmed that the recycling process can be applied repeatedly.

\section{$3.4 \mathrm{NiO}$}

Even though $\mathrm{Cu}$ has attracted considerable attention as an alternative to Ag owing to its cost-effectiveness and superior conductivity, $\mathrm{Cu}$ electrodes are vulnerable to oxidation under high-temperature and high-humidity conditions and are susceptible to corrosion in aggressive media. In contrast to $\mathrm{Cu}, \mathrm{Ni}$ has a high corrosion 


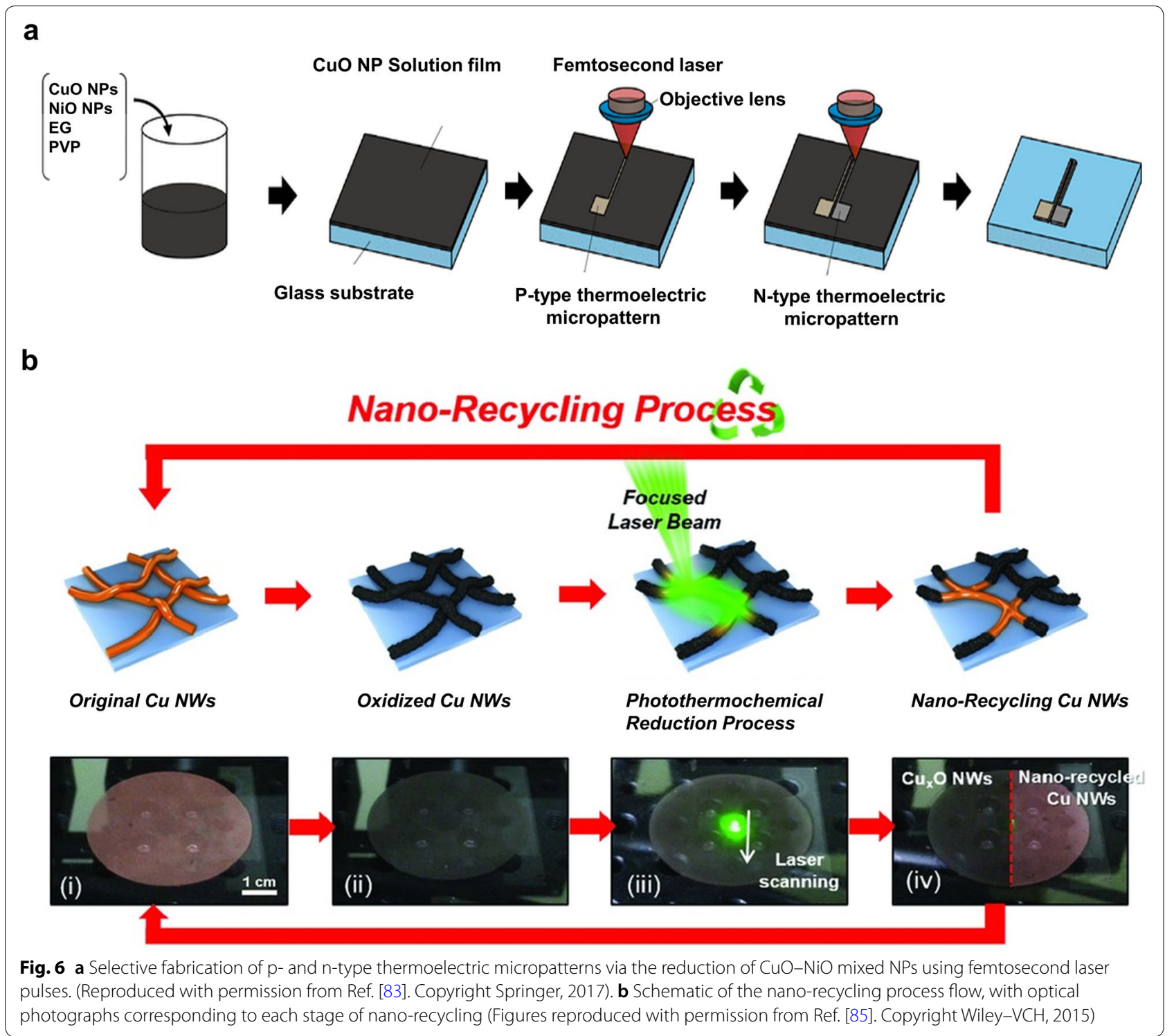

resistance and heat resistance, along with a color similar to that of Ag; hence, it is widely used for plating metals [86-88], composite materials [89-91], and catalysts in electrochemical devices $[92,93]$. On the other hand, $\mathrm{NiO}$ can be used as a semiconductor electrode for various applications, such as resistive switching memory $[94,95]$, batteries [96, 97], sensors [98, 99], solar cells [100, 101], and organic light-emitting devices [102-104]. Research on the fabrication of Ni electrodes using NPs was conducted later than research on the aforementioned materials. Similar to the case of $\mathrm{Cu}, \mathrm{Ni}$ nanostructures are easily oxidized, resulting in oxide forms. Thus, in the fabrication of $\mathrm{Ni}$ electrodes using $\mathrm{NiO}$ NPs via the laser process, reduction and sintering should occur simultaneously. Lee et al. employed LDP for high-resolution Ni electrode fabrication on glass and PI substrates using solution-processed $\mathrm{NiO}_{x} \mathrm{NP}$ thin films, as shown in Fig. 7a-f [105]. The nonstoichiometric $\mathrm{NiO}_{x}$ NPs employed in this process had a narrower bandgap $(\sim 2.28 \mathrm{eV})[106]$ than those used in other studies $(>3.4 \mathrm{eV})[93,107]$ because of the higher density of oxygen vacancies; thus, 514.5-nm laser irradiation was easily absorbed by the NP thin film. Welldispersed NP ink containing extremely small and uniform-sized $\mathrm{NiO}_{x}$ NPs resulted in an extremely smooth and uniform surface morphology. The $\mathrm{NiO}_{x} \mathrm{NP}$ ink used in the study did not include EG or PVP; these substances played critical roles as reducing agents for $\mathrm{CuO}$ in other studies $[77-79,85]$. Therefore, the reduction of the $\mathrm{NiO}_{\mathrm{x}} \mathrm{NPs}$ occurred via a different route [106]. (1) Laser irradiation induced a rapid temperature increase of 
(See figure on next page.)

Fig. 7 a TEM image of synthesized $\mathrm{NiO}_{x} N$ Ps. $\mathbf{b}$ Spin-coated $\mathrm{NiO}_{x}$ thin film on a glass substrate. $\mathbf{c}$ SEM image of the surface of the $\mathrm{NiO}_{x}$ film shown in b. d, e Top-view SEM images of mesh-type electrodes with different magnifications. The insets in $\mathbf{d}$ show elemental mapping images obtained via energy-dispersive X-ray spectroscopy. $\mathbf{f}$ Mesh-type Ni electrodes with different pitches on a PI substrate. The top and bottom insets show bright-field microscopic images of the mesh patterns generated with 20- and 80- $\mu \mathrm{m}$ pitches, respectively (a-f reproduced with permission from Ref. [105]. Copyright American Chemical Society 2014). $\mathbf{g}$ Schematics of the overall experimental procedures of the NiO NP inkjet printing and sintering processes; (i) $\mathrm{NiO}$ inkjet printing, (ii) hotplate (oven) sintering for $\mathrm{NiO}$ electrodes, (iii) selective laser reductive sintering for $\mathrm{Ni}$ electrodes, and (iv) removal of un-sintered parts via washing. $\mathbf{h}$ Photographs of Ni patterns formed by laser reductive sintering after washing to remove non-irradiated parts. The inset shows a cross-sectional profile of the Ni pattern. $\mathbf{i}, \mathbf{j}$ Single dot of $\mathrm{Ni}$ and Ni/NiO hybrid electrode, respectively, obtained via laser reductive sintering. The scale bars indicate $20 \mu \mathrm{m}(\mathbf{g}-\mathbf{j}$ reproduced with permission from Ref. [108]. Copyright Royal Society of Chemistry, 2016)

the $\mathrm{NiO}_{\mathrm{x}} \mathrm{NP}$ film, resulting in the decomposition of the residual toluene solvent in the film, as well as interband excitation of the electrons in the $\mathrm{NiO}_{x}$ NP. (2) Protons generated by toluene decomposition and free electrons donated by the NPs contributed to the reduction process. (3) The reduced NPs were fused together, completing the sintering process. The role of the residual solvent in the reduction reaction was verified, as the reduction did not occur in the case of laser irradiation of the completely dried thin film. The lowest resistivity of the $\mathrm{Ni}$ electrode was calculated to be approximately $63 \mu \Omega \mathrm{cm}$, which is approximately 9 times higher than that of bulk $\mathrm{Ni}(6.93 \mu \Omega \mathrm{cm}$ at room temperature), probably owing to the nanopores created in the sintered electrodes, re-oxidation, or incomplete reduction. Later, Rho et al. used a combination of inkjet printing and the LRS process for $\mathrm{Ni}$ electrode fabrication, as shown in Fig. 7g-j [108]. Instead of spin-coating the $\mathrm{NiO} \mathrm{NPs}$, the authors employed a drop-on-demand inkjet printing system to generate arbitrary $\mathrm{NiO}_{x}$ dot arrays and line patterns on specific parts of the substrate. Inkjet printing is beneficial for minimizing NP ink waste and unwanted contamination of the substrate. Subsequent laser reductive sintering applied to the patterns successfully converted the $\mathrm{NiO}_{\mathrm{x}}$ into conductive Ni electrodes. Furthermore, a half- $\mathrm{NiO} /$ half-Ni electrode structure was obtained by applying oven sintering and the laser process consecutively.

Recently, Nam et al. developed an LRS process to fabricate $\mathrm{Ni}$ electrodes by employing another type of $\mathrm{NiO}_{x}$ NP ink that can be produced on a large scale. To produce $\mathrm{NiO}_{x} \mathrm{NPs}$, a large amount of $\mathrm{Ni}(\mathrm{OH})_{2}$ was easily prepared via the chemical precipitation method followed by calcination. $\mathrm{NiO}_{\mathrm{x}} \mathrm{NPs}$ were dispersed in 1-pentanol with PVP and cetyltrimethylammonium bromide (CTAB), which functioned as a reducing agent and a dispersant. Subsequent LDP on the spin-coated $\mathrm{NiO}_{x}$ NP film generated $\mathrm{Ni}$ electrode patterns even on PET substrates (Fig. 8a) [20]. Upon CW laser irradiation $(\lambda=532 \mathrm{~nm})$, PVP was decomposed, yielding carboxylic acid, which reduced the $\mathrm{NiO}_{\mathrm{x}} \mathrm{NPs}$ to Ni NPs. Because the reduction reaction was observed even on a completely dried $\mathrm{NiO}_{x}$
NP thin film, it was concluded that the residual solvent was not an essential component for the reduction in this case. Compared with $\mathrm{Cu}$ electrodes, $\mathrm{Ni}$ electrodes exhibited distinct properties, such as excellent oxidation resistance (up to $400{ }^{\circ} \mathrm{C}$ ) and high corrosion resistance in both water and seawater, as shown in Fig. 8b, c [20]. The lowest resistivity of the $\mathrm{Ni}$ electrode was approximately $98.9 \mu \Omega \mathrm{cm}$, which is sufficiently low to apply the electrode to a flexible resistive touch screen panel or a transparent heater. For example, the mesh-patterned $\mathrm{Ni}$ panels on PET exhibited a high transparency $(T=84 \%)$ and low sheet resistance $\left(R_{\mathrm{s}}=53 \Omega \mathrm{sq}^{-1}\right)$. Furthermore, high mechanical flexibility and electrical stability of the $\mathrm{Ni}$ electrodes on PET were confirmed by various tests such as ultrasonic-bath, tape-pull, bending/twisting, and cyclic bending tests. More recently, a monolithic seamless $\mathrm{Ni}-\mathrm{NiO}-\mathrm{Ni}$ heterostructure was fabricated via the LDP process (Fig. 8d) [109]. In that study, 532-nm CW laser irradiation not only promoted photothermochemical reduction and the sintering of the NiO NPs to pattern the $\mathrm{Ni}$ electrodes but also induced reductive rapid thermal annealing of NiO NPs located between two Ni electrodes, forming a $\mathrm{NiO}$ sensing channel. Because the $\mathrm{Ni}$ electrodes and the $\mathrm{NiO}$ sensing channel were formed on a single layer, they formed a monolithic contact without any contact resistance, and no alignment process was required. Furthermore, the low-heat budget of the laser process allowed fabrication of the flexible structure even on a $25-\mu \mathrm{m}$-thick (ultrathin) PET substrate. Importantly, the unique thermal activation mechanism originating from the laser process enhanced the temperature sensitivity. The LDP process of NiO NPs has also been employed to produce Ni-based composite microstructures. Mizoshiri et al. used a high-repetition rate femtosecond laser $(\lambda=780 \mathrm{~nm}$, pulse width $=120 \mathrm{fs}$, repetition rate $=80 \mathrm{MHz}$ ) to fabricate $\mathrm{Ni}-\mathrm{Cu} / \mathrm{NiO}-\mathrm{Cu}_{2} \mathrm{O}$ micropatterns using a mixture of $\mathrm{NiO}$ and $\mathrm{CuO}$ NPs $[82,83]$ and fabricate $\mathrm{Ni}-\mathrm{Cr}$ composites using $\mathrm{NiO} / \mathrm{Cr}$ mixed NPs [110]. In these studies, the authors manipulated the laser scanning speed to control the chemical compositions of the composites. 

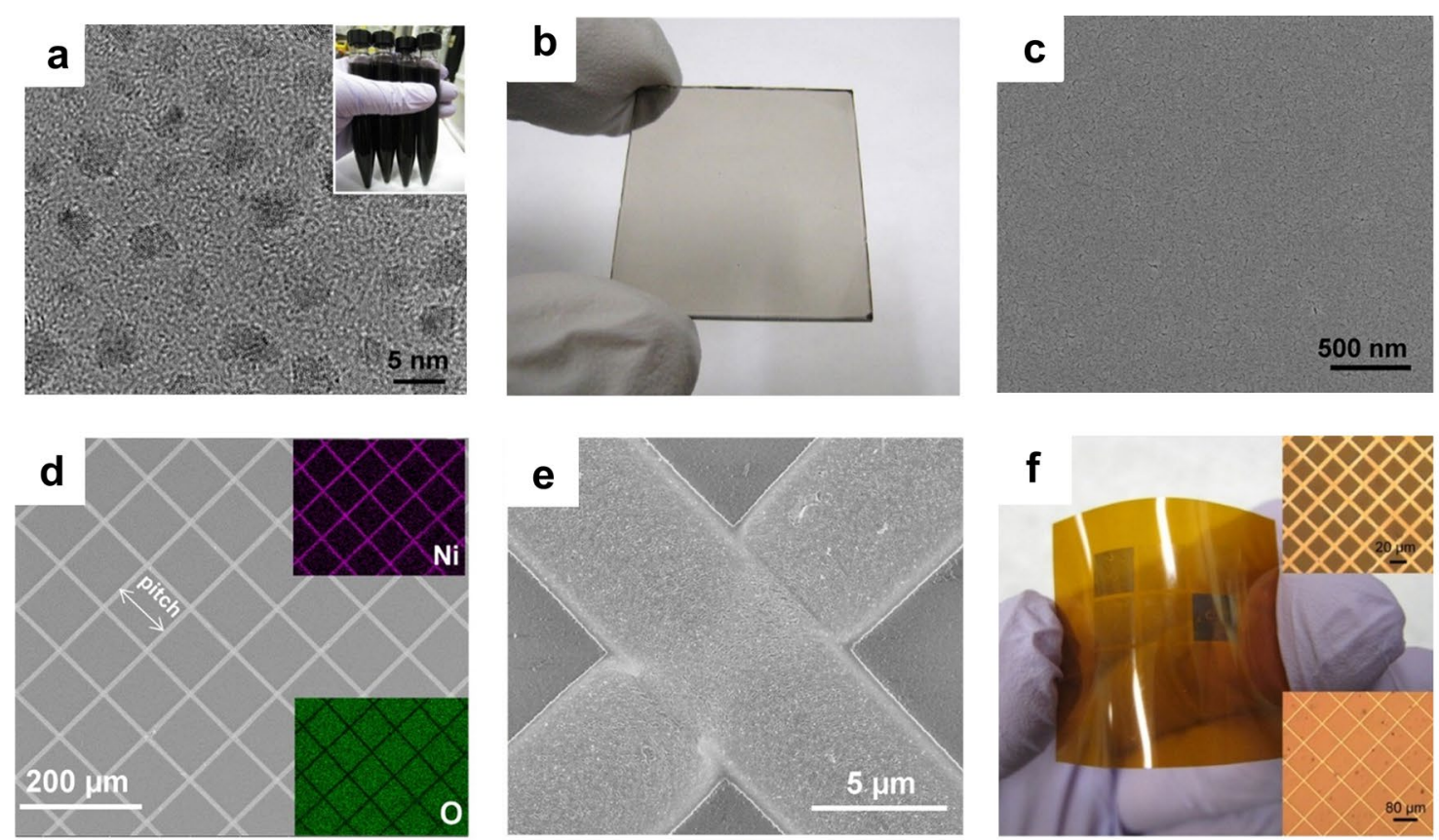

g

(ii)

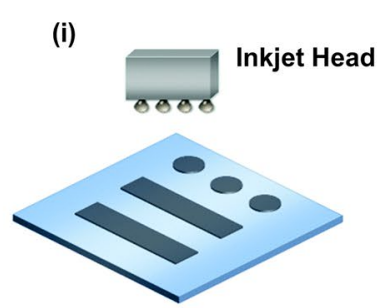

NiO NP inkjet printing
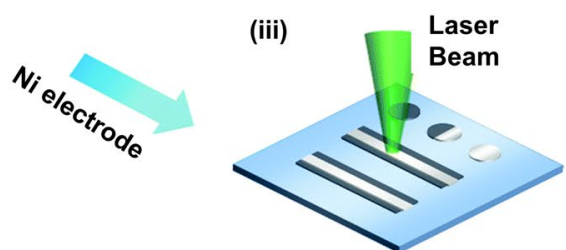

Selective laser reductive sintering

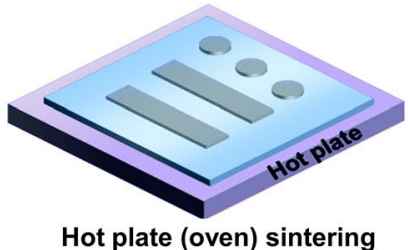

Hot plate (oven) sintering
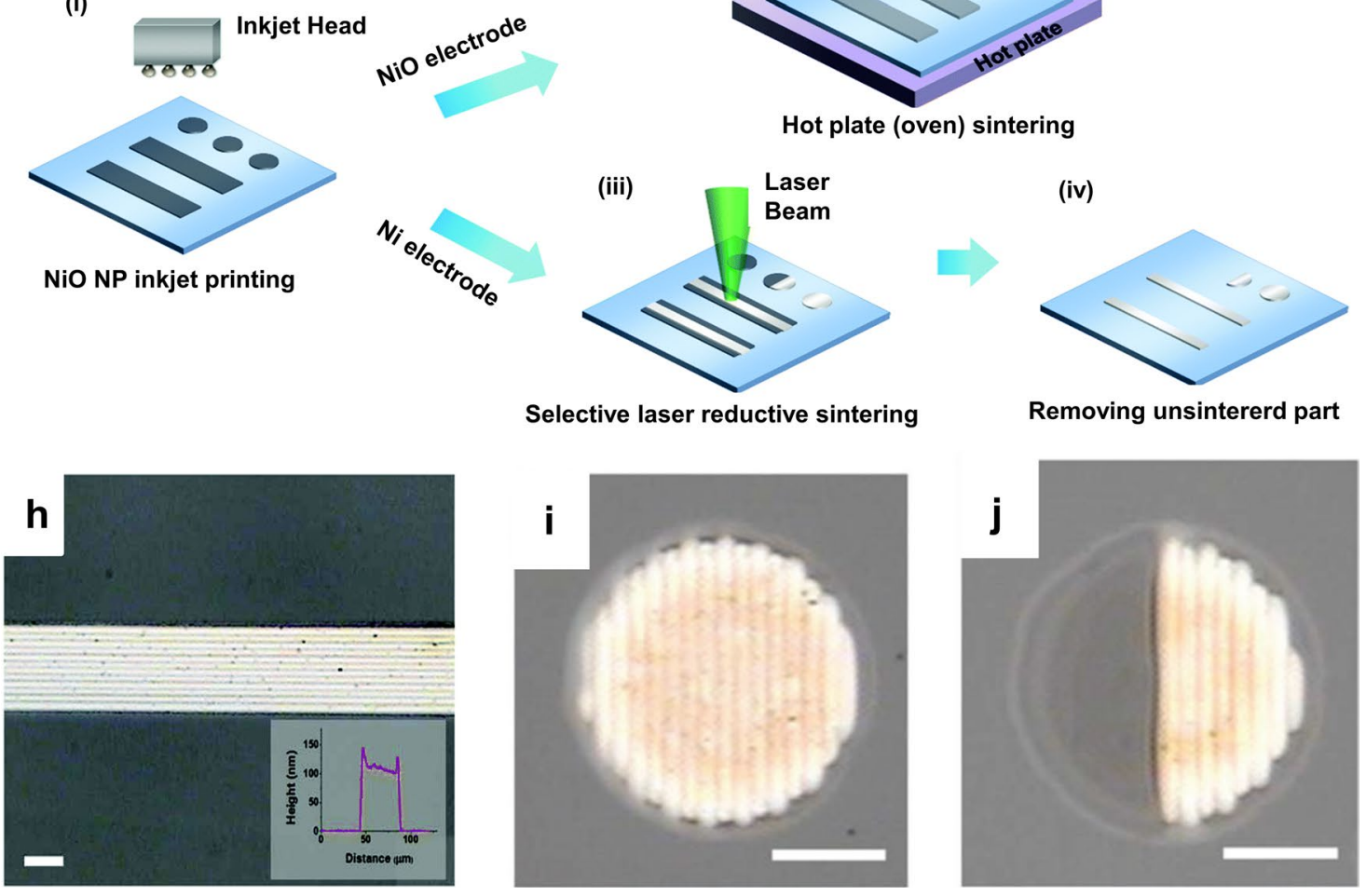

\section{Conclusions and outlook}

Recent studies on the LDP process for metal oxide nanomaterials such as ITO, $\mathrm{ZnO}, \mathrm{CuO}$, and $\mathrm{NiO}$ in the context of fabricating conductive electrodes were reviewed. The reviewed studies are summarized in Table 1 . It is noted that the transmittance value is included in Table 1 when 


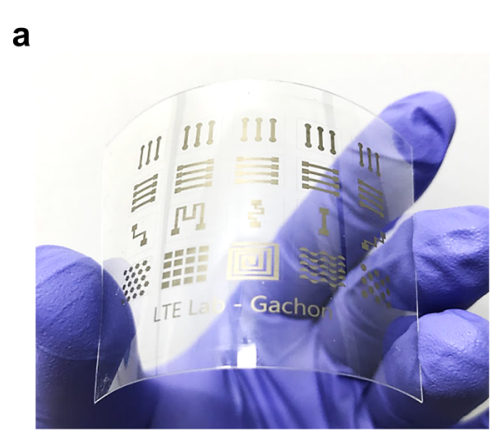

b

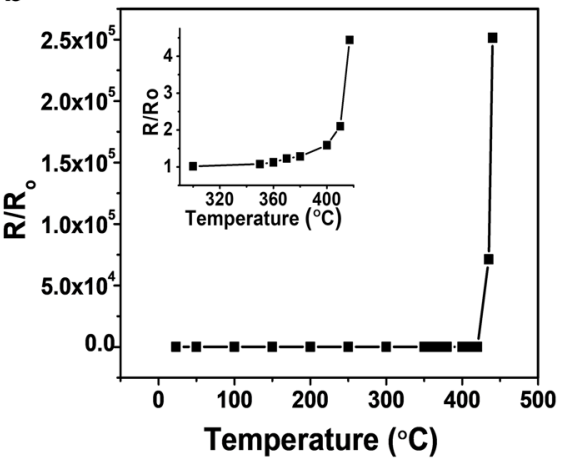

C

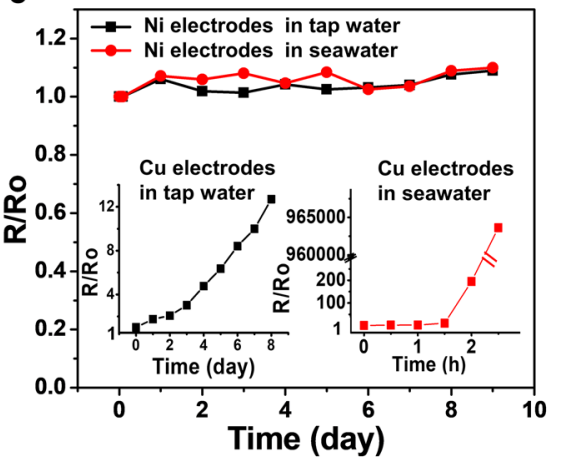

d

Seamless Monolithic Fabrication of Sensing Channel (NiO) and Electrode (Ni)

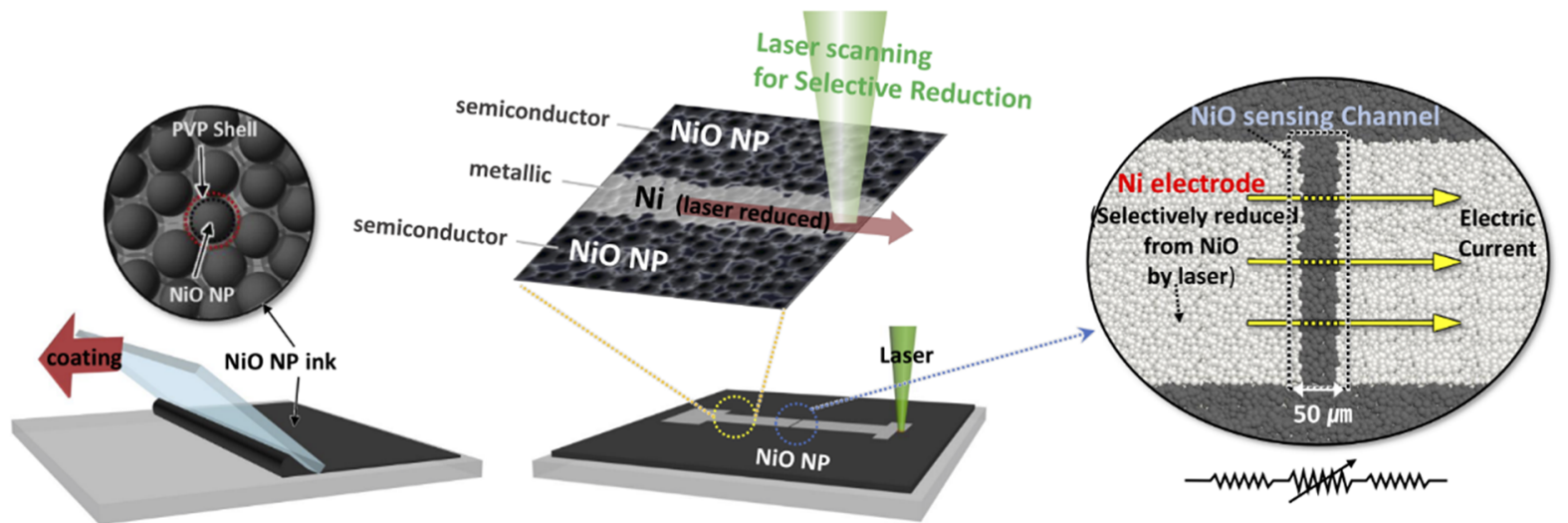

Fig. 8 a Customized Ni conductor patterns on a PET substrate. b Relative resistance variation $\left(R / R_{0}\right)$ with an increase in the temperature from room temperature to $440{ }^{\circ} \mathrm{C}$. The inset shows a magnified view in the temperature range of $300-420^{\circ} \mathrm{C}$. $\mathbf{c}$ Measured R/Ro of Ni electrodes in tap water and seawater. The insets show the measured R/Ro values of the Cu electrodes in tap water (left) and seawater (right) (a-c reproduced with permission from Ref. [20]. Copyright Wiley-VCH, 2019). d Schematic of the monolithic LRS process. NiO NP ink is coated on a substrate via the doctor blading technique. Selective laser irradiation of the dried $\mathrm{NiO}$ layer using a computer-aided galvano-mirror system and a monolithic Ni-NiO-Ni structure having a NiO-channel (several tens of micrometers wide) formed via the simple hatching technique (d reproduced with permission from Ref. [109]. Copyright Wiley-VCH, 2020)

a transparent panel fabrication is demonstrated in the study. The LDP process for metal oxides provides a facile and versatile fabrication route compared with the conventional photolithography process, which is complex, expensive, and time-consuming. By exploiting the unique characteristics of lasers, it is possible to induce physical, chemical, and electrical changes in the material properties on heat-sensitive substrates that cannot be achieved using ordinary heat and light sources. Additionally, because the process is localized and selective, arbitrary electrode patterns can be generated in the desired form without using a photomask, and the pattern design can be modified by simply changing the drawing in the CAD system linked to the laser scanner. More importantly, the laser-induced photochemical or photothermochemical reaction allows the use of metal oxides instead of expensive noble metals as starting materials for the production of conductive electrodes, which is advantageous with regard to handling, storage, and mass production.

The future LDP process of metal oxide nanomaterials is expected to expand both practical and theoretical aspects. The material used in the LDP process needs to be more diversified, and the application field needs to be further developed. Additionally, the reduction, sintering, and heat transfer phenomena that occur during the laserinduced modification of the physical, chemical properties of metal oxide NPs have to be theoretically explored more clearly. There are still several challenges and limitations related to the LDP process. However, the process obviously has unique advantages and is worth to be developed continuously as a method that can be used together with or as an alternative for conventional ones to produce next-generation transparent conductors, sensors, and electronics. Since the LDP process can be applied on the thermally vulnerable polymer substrates, we expect that 
Table 1 Summary of studies on the laser digital patterning process using metal oxide nanomaterials

\begin{tabular}{|c|c|c|c|c|c|c|}
\hline Metal oxide & Solvent for NP ink & Laser & Substrate & Electrical properties & $\begin{array}{l}\text { Transmittance } \\
\text { @ 550 nm }\end{array}$ & Refs. \\
\hline ITO & Ethanol & $\mathrm{ns}, 248 \mathrm{~nm}$ & PET & $\rho=1.1 \times 10^{-2} \Omega \mathrm{cm}$ & $66 \%$ & [30] \\
\hline ITO & Ethanol & $\mathrm{cw}, 10.6 \mu \mathrm{m}$ & PET & $R_{\mathrm{s}} \sim 400 \Omega \mathrm{sq}^{-1}\left(\rho=12 \times 10^{-2} \Omega \mathrm{cm}\right)$ & $80 \%$ & [32] \\
\hline ITO & Alcoholic solvent & $\mathrm{ps}, 1.75 \mu \mathrm{m}$ & PET & $R_{\mathrm{s}} \sim 300 \Omega \mathrm{sq}^{-1}$ & $80 \%$ & [33] \\
\hline ITO & Commercial suspension & $\mathrm{cW}, 1.5 \mu \mathrm{m}$ & Glass & $R_{\mathrm{s}} \sim 80 \Omega \mathrm{sq}^{-1}\left(\rho=1.3 \times 10^{-3} \Omega \mathrm{cm}\right)$ & $75 \%$ & [29] \\
\hline $\mathrm{ZnO}$ & Ethanol, Ethylene glycol & $\mathrm{ns}, 248 \mathrm{~nm}$ & $\mathrm{SiO}_{2}$ & $R=3.4 \times 10^{4} \mathrm{M} \Omega \rightarrow 78 \mathrm{M} \Omega$ & - & [42] \\
\hline $\mathrm{ZnO}$ & 1-pentanol & ps, 355 nm & Quartz & $R_{\mathrm{s}} \sim 5 \mathrm{k} \Omega \mathrm{sq}^{-1}\left(\rho=4.75 \times 10^{-2} \Omega \mathrm{cm}\right)$ & $84 \%$ & [44] \\
\hline $\mathrm{ZnO}$ & Methanol, Butyl acetate & $\mathrm{cW}, 1065 \mathrm{~nm}$ & Glass, Na-CMC & $\rho=0.9 \times 10^{-4} \Omega \mathrm{cm}$ & - & [55] \\
\hline $\mathrm{CuO}$ & Ethylene glycol & $c w \& n s 1070 \mathrm{~nm}$ & Glass, PI & $\rho=31 \times 10^{-6} \Omega \mathrm{cm}$ & - & [77] \\
\hline $\mathrm{CuO}$ & IPA & $\mathrm{ns}, 1070 \mathrm{~nm}$ & Glass & $\rho=13 \times 10^{-6} \Omega \mathrm{cm}$ & - & [78] \\
\hline $\mathrm{CuO}$ & Ethylene glycol & $\mathrm{ns}, 1070 \mathrm{~nm}$ & PET & $\rho=30 \times 10^{-6} \Omega \mathrm{cm}$ & - & [81] \\
\hline $\mathrm{CuO} / \mathrm{NiO}$ & Ethylene glycol & $\mathrm{fs}, 780 \mathrm{~nm}$ & Glass & - & - & [83] \\
\hline $\mathrm{CuO} / \mathrm{GO}$ & Water & $\mathrm{cW}, 405 \mathrm{~nm}$ & PET & $R_{\mathrm{s}}=19.6 \Omega \mathrm{sq}^{-1}$ & - & [84] \\
\hline $\mathrm{Cu}_{\mathrm{x}} \mathrm{O}$ & Isopropyl alcohol, Ethylene glycol & cW, $532 \mathrm{~nm}$ & Glass & $R=$ over $10000 \Omega \rightarrow 91 \Omega$ & - & [85] \\
\hline $\mathrm{NiO}_{x}$ & Toluene & cW, $514.5 \mathrm{~nm}$ & Glass, PI & $R_{\mathrm{s}}=655 \Omega \mathrm{sq}^{-1}\left(\rho=63 \times 10^{-6} \Omega \mathrm{cm}\right)$ & $87 \%$ & [105] \\
\hline $\mathrm{NiO}_{x}$ & Toluene & $\mathrm{cW}, 532 \mathrm{~nm}$ & Glass & $\rho=103 \times 10^{-6} \Omega \mathrm{cm}$ & - & [108] \\
\hline $\mathrm{NiO}_{x}$ & 1-pentanol & $\mathrm{cW}, 532 \mathrm{~nm}$ & Glass, PI, PET & $R_{\mathrm{s}}=53 \Omega \mathrm{sq}^{-1}\left(\rho=98.8 \times 10^{-6} \Omega \mathrm{cm}\right)$ & $84 \%$ & [20] \\
\hline $\mathrm{NiOx}$ & 1-pentanol & $\mathrm{cW}, 532 \mathrm{~nm}$ & PET & - & - & [109] \\
\hline $\mathrm{NiO} / \mathrm{Cr}$ & Ethylene glycol & $\mathrm{fs}, 780 \mathrm{~nm}$ & Glass & $\rho=290 \Omega \mathrm{cm}$ & & [110] \\
\hline
\end{tabular}

$\rho$ resistivity, $R_{\mathrm{s}}$ sheet resistance, $R$ resistance, $n s$ nanosecond, $c W$ continuous-wave, $p s$ picosecond, $f s$ femtosecond

the LDP process will become a mainstream tool for the development of flexible and stretchable electronics [111$120]$ in the future.

\begin{abstract}
Abbreviations
LDP: Laser digital patterning; NP: Nanoparticle; CW: Continuous-wave; CAD: Computer-aided design; ITO: Indium-doped din oxide; PET: Polyethylene terephthalate; IR: Infrared; UV: Ultraviolet; FET: Field-effect transistor; AZO: Al-doped $\mathrm{ZnO}$; TEM: Transmission electron microscopy; $\rho$ : Resistivity; $R_{s}$ : Sheet resistance; ns: Nanosecond; cw: Continuous-wave; ps: Picosecond; fs: Femtosecond; MPTS: 3-Methacryloxypropyl-trimethoxysilane; Na-CMC: Sodium carboxymethyl cellulose; APG: Atmospheric-pressure glow; IPL: Intense pulsed light; LRS: Laser-induced reductive sintering; PVP: Polyvinylpyrrolidone; EG: Ethylene glycol; PI: Polyimide; XRD: X-ray diffraction; T: Glass transition temperature; GO: Graphene oxide; rGO: Reduced graphene oxide; NR: Nanorod; NW: Nanowire; CTAB: Cetyltrimethylammonium bromide; IPA: Isopanol.
\end{abstract}

\section{Acknowledgements}

Not applicable.

\section{Authors' contributions}

$D L$ and JR supervised the overall conception. VBN, TTG, SK, JR, and DL wrote the manuscript. VBN, TTG, and SK contributed equally to this work. All authors designed figure sets and analyzed the literature. All authors read and approved the final manuscript.

\section{Funding}

This work was financially supported by the National Research Foundation of Korea (NRF) grant funded by the Korea government (MSIT) (CAMM2019M3A6B3030637), and by the Gachon University research fund of 2019 (GCU-2019-0386).

\section{Availability of data and materials}

The datasets used and/or analyzed during the current study are available from the corresponding author on reasonable request.
Competing interests

The authors declare that they have no competing interests.

\section{Author details}

${ }^{1}$ Department of Chemical Engineering, Pohang University of Science and Technology (POSTECH), Pohang 37673, South Korea. ${ }^{2}$ Laser and Thermal Engineering Lab, Department of Mechanical Engineering, Gachon University, Seongnam 13120, South Korea. ${ }^{3}$ Advanced Laser Fabrication Systems Lab, Department of Mechanical Engineering, Incheon National University, Incheon 22012, South Korea. ${ }^{4}$ Department of Mechanical Engineering, Pohang University of Science and Technology (POSTECH), Pohang 37673, South Korea.

Received: 8 May 2020 Accepted: 23 June 2020

Published online: 06 July 2020

References

1. S. Torii, W.-J. Yang, J. Heat Mass Transf. 48, 537-544 (2005)

2. W. Mustafeez, D. Lee, C. Grigoropoulos, A. Salleo, Opt. Express 19, 15452-15458 (2011)

3. J. Yeo, S. Hong, M. Wanit, H.W. Kang, D. Lee, C.P. Grigoropoulos, H.J. Sung, S.H. Ko, Adv. Funct. Mater. 23, 3316-3323 (2013)

4. J.B. In, D. Lee, F. Fornasiero, A. Noy, C.P. Grigoropoulos, ACS Nano 6 , $7858-7866(2012)$

5. J. Chung, H. Lu, X. Ou, H. Zhou, C. Yang, Biomed. Opt. Express 7, 4787-4802 (2016)

6. S.H. Ko, D. Lee, H. Pan, S.-G. Ryu, C.P. Grigoropoulos, N. Kladias, E. Panides, G.A. Domoto, Appl. Phys. A 100, 391-400 (2010)

7. V. Natrajan, K. Christensen, Meas. Sci. Technol. 20, 015401 (2008)

8. P. Zbyszynski, I. Toraason, L. Repp, G.S. Kwon, Nano converg. 6, 22 (2019)

9. I.G. Gonzalez-Martinez, A. Bachmatiuk, T. Gemming, G. Cuniberti, B. Trzebicka, M.H. Rummeli, Nano converg. 6, 14 (2019)

10. D. Paeng, J. Yeo, D. Lee, S.-J. Moon, C.P. Grigoropoulos, Appl. Phys. A 120, 1229-1240 (2015)

11. S.H. Ko, Semicond. Sci. Technol. 31, 073003 (2016) 
12. J. Yeo, S. Hong, D. Lee, N. Hotz, M.-T. Lee, C. P. Grigoropoulos, and S. H. Ko, PLOS ONE 7 (2012)

13. D. Paeng, J.H. Yoo, J. Yeo, D. Lee, E. Kim, S.H. Ko, C.P. Grigoropoulos, Adv Mater. 27, 2762-2767 (2015)

14. H. Kwon, W. Choi, D. Lee, Y. Lee, J. Kwon, B. Yoo, C.P. Grigoropoulos, S. Kim, Nano Res. 7, 1137-1145 (2014)

15. M.-T. Lee, D. Lee, A. Sherry, C.P. Grigoropoulos, J. Micromech. Microeng 21, 095018 (2011)

16. J. Kwon, H. Cho, Y.D. Suh, J. Lee, H. Lee, J. Jung, D. Kim, D. Lee, S. Hong, S.H. Ko, Adv. Mater. Technol. 2, 1600222 (2017)

17. K. An, S. Hong, S. Han, H. Lee, J. Yeo, S.H. Ko, A.C.S. Appl, Mater. Interfaces 6, 2786-2790 (2014)

18. M. Heo, H. Cho, J.W. Jung, J.R. Jeong, S. Park, J.Y. Kim, Adv. Mater. 23, 5689-5693 (2011)

19. Z. Peng, B. Spliethoff, B. Tesche, T. Walther, K. Kleinermanns, J. Phys. Chem. B 110, 2549-2554 (2006)

20. V.B. Nam, J. Shin, Y. Yoon, T.T. Giang, J. Kwon, Y.D. Suh, J. Yeo, S. Hong, S.H. Ko, D. Lee, Adv. Funct. Mater. 29, 1806895 (2019)

21. H. Kim, C.M. Gilmore, A. Pique, J.S. Horwitz, H. Mattoussi, H. Murata, Z.H. Kafafi, D.B. Chrisey, J. Appl. Phys. 86, 6451-6461 (1999)

22. H. Ohta, M. Orita, M. Hirano, H. Tanji, H. Kawazoe, H. Hosono, Appl. Phys. Lett. 76, 2740-2742 (2000)

23. K. Sakamoto, H. Kuwae, N. Kobayashi, A. Nobori, S. Shoji, J. Mizuno, Sci. Rep. 8, 2825 (2018)

24. M. Aleksandrova, G. Kolev, I. Cholakova, G. Dobrikov, G. Bodurov, Int. J. Thin Film. Sci. Tec. 2, 67-75 (2013)

25. T. Park, J. Ha, D. Kim, Thin Solid Films 658, 38-45 (2018)

26. G. Račiukaitis, M. Brikas, M. Gedvilas, T. Rakickas, Appl. Surf. Sci. 253, 6570-6574 (2007)

27. J. Chae, L. Jang, K. Jain, Mater. Lett. 64, 948-950 (2010)

28. G. Frank, H. Köstlin, Appl. Phys. A 27, 197-206 (1982)

29. H. Pan, D. Lee, S.H. Ko, C.P. Grigoropoulos, H.K. Park, T. Hoult, Appl. Phys. A 104, 29-38 (2011)

30. T. Park, D. Kim, Thin Solid Films 578, 76-82 (2015)

31. H. Peelaers, E. Kioupakis, C. Van de Walle, Phys. Rev. B 92, 235201 (2015)

32. T. Königer, T. Rechtenwald, I. Al-Naimi, T. Frick, M. Schmidt, H. Münstedt, J. Coat. Technol. Res. 7, 261-269 (2010)

33. A. Serkov, H. Snelling, S. Heusing, T.M. Amaral, Sci. Rep. 9, 1-8 (2019)

34. G. Fiaschi, S. Mirabella, G. Franzò, L. Maiolo, A. Chitu, Y. Komem, Y Shacham-Diamand, Appl. Surf. Sci. 458, 800-804 (2018)

35. M. Nakata, K. Takechi, T. Eguchi, E. Tokumitsu, H. Yamaguchi, S. Kaneko, Jpn. J. Appl. Phys. 48, 081608 (2009)

36. C.-Y. Tsay, M.-C. Wang, Ceram. Int. 39, 469-474 (2013)

37. I. Ozerov, M. Arab, V.I. Safarov, W. Marine, S. Giorgio, M. Sentis, L. Nanai, Appl. Surf. Sci. 226, 242-248 (2004)

38. J.-J. Kim, J.-Y. Bak, J.-H. Lee, H.S. Kim, N.-W. Jang, Y. Yun, W.-J. Lee, Thin Solid Films 518, 3022-3025 (2010)

39. K. Kim, S. Kim, S.Y. Lee, Curr. Appl. Phys. 12, 585-588 (2012)

40. T. Yen, D. Strome, S.J. Kim, A.N. Cartwright, W.A. Anderson, J. Electro. Mater. 37, 764-769 (2008)

41. R. Winfield, L. Koh, S. O'Brien, G.M. Crean, Appl. Surf. Sci. 254, 855-858 (2007)

42. H. Pan, N. Misra, S.H. Ko, C.P. Grigoropoulos, N. Miller, E.E. Haller, O. Dubon, Appl. Phys. A 94, 111-115 (2009)

43. B. Norris, J. Anderson, J. Wager, D. Keszler, J. Phys. D Appl. Phys. 36, L105 (2003)

44. D. Lee, H. Pan, S.H. Ko, H.K. Park, E. Kim, C.P. Grigoropoulos, Appl. Phys. A 107, 161-171 (2012)

45. M. Berber, V. Bulto, R. Kliß, H. Hahn, Scr. Mater. 53, 547-551 (2005)

46. Y. Li, R. Yao, H. Wang, X. Wu, J. Wu, X. Wu, W. Oin, A.C.S. Appl, Mater. Interfaces 9, 11711-11720 (2017)

47. J.H. Jun, K. Cho, J. Yun, K.S. Suh, T. Kim, S. Kim, Org. Electron. 9, 445-451 (2008)

48. E. Lee, T.H. Kim, S.W. Lee, J.H. Kim, J. Kim, T.G. Jeong, J.-H. Ahn, B. Cho, Nano converg. 6, 1-8 (2019)

49. D. Wang, J. Zhou, G. Liu, J. Alloys Compd. 481, 802-805 (2009)

50. S.O. El Hamali, W.M. Cranton, N. Kalfagiannis, X. Hou, R. Ranson, D.C. Koutsogeorgis, Opt Laser Eng 80, 45-51 (2016)

51. W.-T. Hsiao, S.-F. Tseng, C.-K. Chung, D. Chiang, K.-C. Huang, K.-M. Lin, L.-Y. Li, M.-F. Chen, Opt. Laser Technol. 68, 41-47 (2015)
52. Q. Xu, R. Hong, H. Huang, Z. Zhang, M. Zhang, X. Chen, Z.Y. Wu, Opt. Laser Technol. 45, 513-517 (2013)

53. L.-J. Huang, B.-J. Li, N.-F. Ren, Ceram. Int. 42, 7246-7252 (2016)

54. S. Feng, Z. Tian, J. Wang, S. Cao, D. Kong, Adv. Electron. Mater. 5, 1800693 (2019)

55. W. Shou, B.K. Mahajan, B. Ludwig, X. Yu, J. Staggs, X. Huang, H. Pan, Adv. Mater. 29, 1700172 (2017)

56. S. Feng, S. Cao, Z. Tian, H. Zhu, D. Kong, A.C.S. Appl, Mater. Interfaces 11, 45844-45852 (2019)

57. V.B. Nam, D. Lee, Nanomaterials 6, 47 (2016)

58. J. Jung, H. Cho, S.H. Choi, D. Kim, J. Kwon, J. Shin, S. Hong, H. Kim, Y. Yoon, J. Lee, D. Lee, Y.D. Suh, S.H. Ko, A.C.S. Appl, Mater. Interfaces 11 15773-15780 (2019)

59. I. Hong, S. Lee, D. Kim, H. Cho, Y. Roh, H. An, S. Hong, S.H. Ko, S. Han, Nanotechnology 30, 074001 (2018)

60. C.-J. Wu, Y.-J. Sheng, H.-K. Tsao, J. Mater. Chem. C 4, 3274-3280 (2016)

61. Y. Yang, Q. Huang, G.F. Payne, R. Sun, X. Wang, Nanoscale 11, 725-732 (2019)

62. N.-H. Tran, H.-M. Hoang, T.-H. Duong, H.-C. Kim, Appl. Surf. Sci. 146, 216 (2020)

63. S. M. K. Sally Jewell, US Geological Survey: Reston, VA, USA (2014)

64. T. H. Tran and V. T. Nguyen, Int. Sch. Res. Notices. 2014 (2014)

65. X. Lin, F. Sun, MEEP 2018, 208-211 (2019)

66. M.P. Rao, J.J. Wu, A.M. Asiri, S. Anandan, M. Ashokkumar, J Environ Sci 69 $115-124(2018)$

67. Y. Ni, Z. Sun, Z. Zeng, F. Liu, J. Qin, New J. Chem. 43, 18629-18636 (2019)

68. S. Karthikeyan, C. Chuaicham, R.R. Pawar, K. Sasaki, W. Li, A.F. Lee, K. Wilson, J. Mater. Chem. A 7, 20767-20777 (2019)

69. K. Zhang, J.M. Suh, T.H. Lee, J.H. Cha, J.-W. Choi, H.W. Jang, R.S. Varma, M. Shokouhimehr, Nano converg. 6, 6 (2019)

70. P. Mallick, S. Sahu, Nanosci Nanotechnol 2,71-74 (2012)

71. D. Li, X. Zu, D. Ao, Q. Tang, Y. Fu, Y. Guo, K. Bilawal, M.B. Faheem, L. Li, S. Li, Y. Tang, Sensors Actuators B: Chem. 294, 55-61 (2019)

72. J. Toupin, H. Strubb, S. Kressman, V. Artero, N. Krins, C. Laberty-Robert, J. Sol-Gel. Sci. Technol. 89, 255-263 (2019)

73. M. Samouhos, R. Hutcheon, L. Paspaharis, Miner. Eng. 24, 903-913 (2011)

74. Y. Sawada, H. Tamaru, M. Kogoma, M. Kawase, K. Hashimoto, J. Phys. D Appl. Phys. 29, 2539-2544 (1996)

75. J. Ryu, H.-S. Kim, H.T. Hahn, J. Electron. Mater. 40, 42-50 (2011)

76. J.H. Park, S. Han, D. Kim, B.K. You, D.J. Joe, S. Hong, J. Seo, J. Kwon, C.K. Jeong, H.J. Park, T.S. Kim, S.H. Ko, K.J. Lee, Adv. Funct. Mater. 27, 1701138 (2017)

77. B. Kang, S. Han, J. Kim, S. Ko, M. Yang, J. Phys. Chem. C 115, $23664-$ $23670(2011)$

78. H. Lee, M. Yang, Appl. Phys. A 119, 317-323 (2015)

79. M. Mizoshiri, S. Arakane, J. Sakurai, S. Hata, Appl. Phys. Express 9, 036701 (2016)

80. M. Mizoshiri, Y. Ito, S. Arakane, J. Sakurai, S. Hata, Jpn. J. Appl. Phys. 55 06GP05 (2016)

81. S. Back, B. Kang, Opt Laser Eng 101, 78-84 (2018)

82. M. Mizoshiri, K. Nishitani, S. Hata, Micromachines 9, 264 (2018)

83. M. Mizoshiri, S. Hata, Appl. Phys. A 124, 64 (2018)

84. A. Watanabe, M. Aminuzzaman, J. Cai, M. Akhtaruzzaman, S. Ogawa, E. Aoyagi, S. Ito, J. Photopolym, Sci. Technol. 32, 223-226 (2019)

85. S. Han, S. Hong, J. Yeo, D. Kim, B. Kang, M.Y. Yang, S.H. Ko, Adv. Mater. 27, 6397-6403 (2015)

86. C. Gu, J. Lian, J. He, Z. Jiang, Q. Jiang, Surf. Coat. Technol. 200, 5413-5418 (2006)

87. Y. Huang, X. Peng, Y. Yang, H. Wu, X. Sun, X. Han, Met. Mater. Int. 24 $1172-1180(2018)$

88. L. Rao, J. Tang, S. Hu, L. Shen, Y. Xu, R. Li, H. Lin, J. Colloid Interface Sci. 565, 546-554 (2020)

89. J. Song, J. Li, J. Xu, H. Zeng, Nano Lett. 14, 6298-6305 (2014)

90. D. Tishkevich, A. Vorobjova, D. Shimanovich, D. Vinnik, T. Zubar, A. Kozlovskiy, M. Zdorovets, D. Yakimchuk, S. Trukhanov, A. Trukhanov, J. Alloys Compd. 804, 139-146 (2019)

91. P. Mardiha, A. Bahrami, and A. Mohammadnejad, Sci. Sinter. 51 (2019)

92. Z. Han, F. Qiu, R. Eisenberg, P.L. Holland, T.D. Krauss, Science $\mathbf{3 3 8}$ $1321-1324(2012)$ 
93. K. Fominykh, J.M. Feckl, J. Sicklinger, M. Döblinger, S. Böcklein, J. Ziegler, L. Peter, J. Rathousky, E.W. Scheidt, T. Bein, D. Fattakhova-Rohlfing, Adv. Funct. Mater. 24, 3123-3129 (2014)

94. H.-W. Yun, H.K. Woo, S.J. Oh, S.-H. Hong, Curr. Appl. Phys. 20, 288-292 (2020)

95. E.M. Lee, Y. Ahn, J.Y. Son, J. Alloys Compd. 840, 155748 (2020)

96. K. Park, B. Choi, J. Alloys Compd. 766, 470-476 (2018)

97. K. Min, C. Jung, D.S. Ko, K. Kim, J. Jang, K. Park, E. Cho, A.C.S. Appl, Mater. Interfaces 10, 20599-20610 (2018)

98. S.M. Majhi, G.K. Naik, H.-J. Lee, H.-G. Song, C.-R. Lee, I.-H. Lee, Y.-T. Yu, Sensors Actuators B: Chem. 268, 223-231 (2018)

99. L. Sui, T. Yu, D. Zhao, X. Cheng, X. Zhang, P. Wang, Y. Xu, S. Gao, H. Zhao, Y. Gao, L. Huo, J. Hazard. Mater. 385, 121570 (2020)

100. U. Kwon, B.-G. Kim, D.C. Nguyen, J.-H. Park, N.Y. Ha, S.-J. Kim, S.H. Ko, S. Lee, D. Lee, H.J. Park, Sci. Rep. 6, 30759 (2016)

101. K. Silambarasan, J. Archana, S. Athithya, S. Harish, R.S. Ganesh, M. Navaneethan, S. Ponnusamy, C. Muthamizhchelvan, K. Hara, Y. Hayakawa, Appl. Surf. Sci. 501, 144010 (2020)

102. J. Kim, H.J. Park, C.P. Grigoropoulos, D. Lee, J. Jang, Nanoscale 8 , 17608-17615 (2016)

103. C.-T. Malvin, C.-T. Tsai, Y.-Y. Wang, P.-C. Chen, S-YChu Kao, J. Alloys Compd. 797, 159-165 (2019)

104. Malvin, C.-T. Tsai, Y.-Y. Chen, P.-C. Kao, and S.-Y. Chu, Solid-State Electron. 158, 85-91 (2019)

105. D. Lee, D. Paeng, H.K. Park, C.P. Grigoropoulos, ACS Nano 8, 9807-9814 (2014)
106. D. Paeng, D. Lee, J. Yeo, J.-H. Yoo, F.I. Allen, E. Kim, H. So, H.K. Park, A.M. Minor, C.P. Grigoropoulos, J. Phys. Chem. C 119, 6363-6372 (2015)

107. P. Patil, L. Kadam, Appl. Surf. Sci. 199, 211-221 (2002)

108. Y. Rho, K.-T. Kang, D. Lee, Nanoscale 8, 8976-8985 (2016)

109. J. Shin, B. Jeong, J. Kim, V. B. Nam, Y. Yoon, J. Jung, S. Hong, H. Lee, H. Eom, J. Yeo, J. Choi. D. Lee, S. H. Ko, Adv. Mater. 32, 1905527 (2019)

110. K. Tamura, M. Mizoshiri, J. Sakurai, and S. Hata "Jpn. J. Appl. Phys. 56 06GN08 (2017)

111. Y. Zhao, A. Kim, G. Wan, B.C. Tee, Nano converg. 6, 25 (2019)

112. C. Parameswaran, D. Gupta, Nano converg. 6, 1-23 (2019)

113. Y. Kim, H. Kim, T.Y. Kim, S.H. Rhyu, D.S. Choi, W.K. Park, C. Yang, D.H. Yoon, W.S. Yang, Carbon 81, 458-464 (2015)

114. T. Chung, J. Han, Y.S. Kim, Nano converg. 6, 1-21 (2019)

115. J. H. Kim, M. J. Han, and S. Seo, J. Polym. Sci., Polym. Phys. 53, 453-460 (2015)

116. H.J. Park, J.H. Yoon, K.G. Lee, B.G. Choi, Nano converg. 6, 9 (2019)

117. D.Y. Kim, M.-J. Kim, G. Sung, J.-Y. Sun, Nano converg. 6, 1-24 (2019)

118. T. Kim, S.J. Son, S. Seo, Appl. Phys. Lett. 93, 013304 (2008)

119. W.S. Lee, S. Jeon, S.J. Oh, Nano converg. 6, 10 (2019)

120. C. Yoon, Nano converg. 6, 1-14 (2019)

\section{Publisher's Note}

Springer Nature remains neutral with regard to jurisdictional claims in published maps and institutional affiliations.

\section{Submit your manuscript to a SpringerOpen ${ }^{\circ}$ journal and benefit from:}

- Convenient online submission

- Rigorous peer review

- Open access: articles freely available online

- High visibility within the field

- Retaining the copyright to your article

Submit your next manuscript at $\gg$ springeropen.com 